\title{
Fetal Neurology: Past, Present and Future
}

\author{
${ }^{1}$ Asim Kurjak, ${ }^{2}$ Panagiotis Antsaklis, ${ }^{3}$ Milan Stanojevic
}

\begin{abstract}
Neurological failure is the most apprehension complication of pregnancy, labor and the neonatal period. The origin and outcome correlation is frequently doubtful. The arrival of fourdimensional ultrasonography (4D US) and its function to study fetal behavior patterns have initiated to offer insight into the structural and functional fetal brain development. Although many fetal behavioral studies have been conducted, it is still questionable whether the assessment of continuity from fetal to neonatal behavior could improve our ability of early detection of brain pathology. Neurological assessment of fetus in utero is extremely difficult even having such sophisticated equipment like 4D ultrasound. As it is well known that quantity of GMs is not so informative and predictive for neurological impairment, their quality should be assessed. Gestalt perception of premature GMs we are dealing with in utero and several weeks postnatally are not as predictive for the detection of neurologically abnormal fetuses or newborns as fidgety GMs. Therefore, some additional parameters should be added to the prenatal neurological examination in order to improve our ability to make the distinction between normal and abnormal fetuses.
\end{abstract}

Keywords: Neurobehavioral development, Fetal behavior, Four-dimensional ultrasound.

How to cite this article: Kurjak A, Antsaklis P, Stanojevic M. Fetal Neurology: Past, Present and Future. Donald School J Ultrasound Obstet Gynecol 2015;9(1):6-29.

Source of support: Nil

Conflict of interest: None

\section{INTRODUCTION}

Understanding the structure and function of the fetal nervous system has been the dream of physicians for centuries. The pioneering efforts of Ian Donald in obstetric ultrasound in the latter part of the 20th century have permitted this dream to become a reality. The initial contribution of obstetric ultrasound focused on normal and abnormal structure. Initially, anencephaly was described and followed by increasingly subtle central

${ }^{1}$ Professor Emeritus, ${ }^{2}$ Senior Lecturer, ${ }^{3}$ Associate Professor

${ }^{1}$ DIU Libertas International University, Zagreb, Croatia

${ }^{2}$ DIU Libertas International University, Teaching Assistant University of Athens, 'Alexandra' Maternity Hospital, Athens, Greece

${ }^{3}$ Department of Obstetrics and Gynecology, Medical School University of Zagreb, DIU Libertas International University Zagreb, Croatia

Corresponding Author: Asim Kurjak, Professor Emeritus, DIU Libertas International University, Zagreb, Croatia, e-mail: asim. kurjak@public.srce.hr nervous system abnormalities such as agenesis of the corpus callosum. The current and evolving challenge for investigators in obstetric ultrasound is to have similar success with the understanding of fetal neurological function. There are many functional neurological abnormalities such as cerebral palsy (CP) whose causes are poorly understood. There are also an escalating number of results illustrating that a large presence of neurological problems, such as minimal cerebral dysfunction, schizophrenia, epilepsy or autism, upshot at least in part from prenatal neurodevelopmental problems. Clinical and epidemiological studies have revealed that $\mathrm{CP}$ most often results from prenatal rather than perinatal or postnatal causes. ${ }^{1}$ Currently, although the momentous advances in prenatal and perinatal care, there is no mean to identify or expect the development of these disorders. Therefore, the development of diagnostic strategies to avoid and condense the saddle of perinatal brain damage has turn into one of the most imperative tasks of contemporary perinatal medicine. The application of the new neurobehavioral test Kurjak's antenatal neurodevelopment test (KANET) might improve our understanding of the prenatal neurodevelopmental events and possibly antenatal detection of cerebral palsy and other neurological diseases.

\section{Structural and Functional Development of Central Nervous System (CNS)}

The development of central nervous system begins approximately at the end of gastrulation. The generation of the neuroectoderm from ectoderm during the third postconceptional week, results in formation of the neural plate. Thus, the neural epithelium of the embryo, which is a precursor of neurons and glia, is virtually the first part of organism that acquires the separate identity from other cells. ${ }^{2}$ The formation of the neural plate is succeeded by the folding of its edges and formation of a neural tube, whose further growth and reshaping results in formation of structures of CNS. According to O'Rahilly and Muller, forebrain (prosencephalon), midbrain (mesencephalon) and hindbrain (rhombencephalon) can be distinguished in the rostral portion of the unfused neural folds ${ }^{3}$ earlier than it is usually referred to, approximately at 22nd postconceptional day. In the rapid succession, during the 4th postconceptional week, the forebrain componentsdiencephalon and telencephalon can be detected. Three 
embryonic zones, ventricular, intermediary and marginal zone (seen from ventricular to pial surface), are present in all parts of neural tube, while telencephalon contains additional two zones, subventricular and subplate zone, Ventricular zone and subventricular zone of telencephalon are the site of neurogenesis and all the future neurons and glia are born in these structures. During migration toward the pial surface they form other transitional zones before reaching their genetically predetermined final destinations. Those destinations are cortical plate or different nuclei in the brain stem, diencephalon and basal forebrain (for references see(1)). One of the transitional structures, a subplate zone that is a site for transient synapses and neuronal interactions, can play a major role in the developmental plasticity following perinatal brain damage. ${ }^{4}$ Early appearance of interneuronal connections, shown in Table 1, implicates a possibility of an early functional development. However, these first synapses exist only temporarily and disappear due to the normal reorganization processes. Most embryonic zones, types of neurons and glia and early synapses, which play crucial role in certain periods of fetal brain development, eventually disappear, significantly changing structure and function of the brain. Reorganization processes include apoptosis, disappearance of redundant synapses, axonal retraction and transposition, and transformation of the neurotransmitters phenotype. ${ }^{4}$ The Table 1 shows a significant overlap of neurogenesis, migration and synaptogenesis in the embryonic and fetal life. Development of human brain is not completed at the time of delivery. In an infant born at term, characteristic cellular layers can be observed in motor, somatosensor, visual and auditory cortical areas. Although, proliferation and migration are completed in a term infant, synaptogenesis and neuronal differentiation continue very intensively. ${ }^{5}$ Brain stem demonstrates high level of maturity, whereas all histogenetic processes actively persist in cerebellum. ${ }^{6}$

Table 1: Dynamics of the most important progressive processes in the development of the human brain

\begin{tabular}{llll}
\hline & Beginning & $\begin{array}{l}\text { Most } \\
\text { intensive } \\
\text { activity }\end{array}$ & Ending \\
\hline Neurogenesis & $\begin{array}{l}\text { Early embryonic } \\
\text { period (4th week) }\end{array}$ & 8th-12th week & $\begin{array}{l}\text { Approx. } \\
\text { 20 } \\
\text { weeks }\end{array}$ \\
& Simultaneously & 18th-24th & 38th \\
Migration & with proliferation & week & week \\
Synaptogenesis & 6th-7th week- & 13th-18th & Puberty \\
& spinal cord & week, after & \\
& 8th week- & 24th week, & \\
& cortical plate & 8th month- & \\
& & 2 years of & \\
& & postnatal life & \\
\hline
\end{tabular}

Therefore, only subcortical formations and the primary cortical areas are well developed in a newborn. Associative cortex, barely visible in a newborn, is scantily developed in a 6 months old infant. Postnatal formation of synapses in associative cortical areas, which intensifies between 8 th month and 2 nd year of life, precedes the onset of first cognitive functions, such as speech. Following the 2nd year of age, many redundant synapses are eliminated. The elimination of synapses begins very rapidly, and continues slowly until the puberty, when the same number of synapses as seen in adults is reached. ${ }^{6}$

\section{The Origins of Fetal Behavior and Fetal Motor Development Assessed by 4D US}

The first synapses appear in the spinal cord at 6 to 7 postconceptional weeks ${ }^{7}$ and in the cortical plate at 8 postconceptional weeks. ${ }^{8}$ This is the phase when the first electrical bustle and conduction of information take places. The earliest spontaneous fetal movements can be observed at 7.5 postconceptional weeks. These movements, consisting of slow flexion and extension of the fetal trunk, accompanied by the inactive displacement of arms and legs and emerging in asymmetrical sequences, have been described as 'vermicular', 9,10 They are substituted by various general movements, which consist of head, trunk and limb movements, such as 'rippling' seen at week 8, 'twitching' and 'strong twitching' at weeks 9 and 9.5, respectively, and 'floating' 'swimming' and 'jumping' at weeks $10 .{ }^{11}$ Isolated limb movements emerge almost simultaneously with the general movements. At the same time with the beginning of spontaneous movements, at 7.5 postconceptional weeks, the initial motor reflex activity can be detected, permitting the hypothesis to be made of the existence of the first afferent-efferent circuits. ${ }^{7}$ At that time, head tilting following perioral stimulation was noted. The primary reflex movements are immense and signify a limited number of synapses in a reflex pathway. During the 8th week of gestation, these substantial reflex movements are replaced with local movements, possibly due to an increase in the number of axodendritic synapses. Hands become susceptible at 10, 5 weeks and lower limbs start to contribute in these reflexes at around weeks 14 . General movements are the first sign of a supraspinal control on fetal motor activity. Approximately at the 7 postconceptional weeks, the brainstem which consists of the medulla oblongata, pons and midbrain, begins to develop and mature in a caudal to rostral direction. As the medulla matures in advance of more rostral structures of brainstem, reflexive movements of the head, body and extremities, as well as breathing movements and heart rate alterations, appear in advance of other functions. ${ }^{12}$ Since, the 10 th week onwards, 
the amount and incidence of movements increase. By 14 to 19 weeks, fetuses are highly active with the longest period between movements of only 5 to 6 minutes. In the 15th week, 15 singular types of movement can be observed. The general body movements and isolated limb movements, retroflexion, anteflexion and rotation of the head can be seen. Also, face movements, such as mouthing, yawning, hiccups, sucking and swallowing, can be included to an ample repertoire of fetal motor activity in this stage. ${ }^{13}$ But, during the first half of pregnancy, a dynamic pattern of neuronal production and migration, as well as the immature cerebral circuits are considered too immature for cerebral involvement in the motor behavior. ${ }^{4}$ Merely at the end of this period do a quantifiable number of synapses appear in the structures preceding the cerebral cortex, perhaps forming a substrate for the first cortical electric activity, noted at weeks $19 .{ }^{4}$ The spinothalamic tract is established at the 20th week and myelinized by 29 weeks of gestation and the thalamocortical connections penetrate the cortical plate at 24 to 26 weeks. Evoked potentials can be detected from the cortex at the 29th week, indicating that the functional connection between periphery and cortex operates from that time onwards. ${ }^{14}$ In the second half of pregnancy, the number of general movements gradually decreases, particulary during the last 10 weeks. ${ }^{15}$ Although, this decrease was first explained as a result of the reduction in amniotic fluid volume, it is now believed to be a result of maturation processes in the brainstem. ${ }^{12}$ Simultaneously with the decline in the number of generalized movements, an increase in facial movements, as well as opening or closing of the jaw, swallowing and chewing, can be observed. These activities can be seen mainly in the periods of absence of general movements, and this pattern is considered to be a manifestation of the normal neurological development of the fetus. ${ }^{15}$ However, alterations not only in the number of movements, but also in their complexity, are revealed to be the result of cerebral maturation processes. It is important to point out that subunits of the brainstem remain the main regulators of all fetal behavioral patterns until delivery. ${ }^{12}$ Despite medical reports from 100 years ago and 25 years of systematic research initiated by Prechtl et al, ${ }^{16-18}$ the study of prenatal behavior is still in its infancy. One of the most promising advances in the field of ultrasonography has been the new $4 \mathrm{D}$ US technology. Its advance has been completed in the last year giving visualizations in almost real-time. ${ }^{19-22}$ The availability of new diagnostic data has in an extraordinary way raised our knowledge about intrauterine life, substantially modifying some earlier interpretations. ${ }^{23}$ First spontaneous fetal movements can be observed with conventional two-dimensional ultrasound (2D US) around 8th gestational week, while the newly developed 4D US allows the visualization of fetal motility 1 week earlier (Table 2). ${ }^{24}$ General movements are the first complex fetal movement patterns observable by 2D US. They can be recognized from the 8th to 9th weeks of pregnancy (Fig. 1) and continue to be present until 16 to 20 weeks after birth. ${ }^{18}$ According to Prechtl, these are gross movements, involving the whole body. They wax and wane in intensity, force and speed, and they have a gradual beginning and end. ${ }^{13,18}$ The majority of sequences of extension and flexion of the legs and arms is complex, and may be better assessed with 4D US. ${ }^{24}$ In the literature, there is a range between the 8 th and 12 th weeks concerning the first appearance of limb movements. $13,18,20,25$ De Vries found isolated arm and leg movements at the 8th week of gestation..$^{13}$ With 4D US, limb movements at the 8th-9th weeks were found. Using $4 \mathrm{D}$ sonography, Kurjak et al found that from 13 gestational weeks onwards, a 'goal orientation' of hand movements appears and a target point can be recognized for each hand movement. ${ }^{19}$ More limb joints are active and move simultaneously, such as extension or flexion in arm and elbow or hip and knee. The elevation of the hand, extension of the elbow joint, with a slight change in direction and rotation, can be seen simultaneously. ${ }^{26}$ The isolated limb movements seen at the 9th week are followed by the appearance of the movements in the elbow joint at 10 weeks, changes in finger position in the 11th week and by easily recognizable clenching and unclenching of the fist at the 12th to 13th weeks. Finally, at the 13th to 14th weeks, isolated finger movements can be seen, as well as an increase in the activity and strength of the hand or finger movements. ${ }^{26}$ Recent investigation of fetuses in the last trimester of gestation, performed by $4 \mathrm{D}$ US, has discovered an even wider range of hand and face movements than was formerly explained. ${ }^{19}$ It has been also confirmed that the fetal movement patterns in the second half of pregnancy are about equal to those monitored after birth, while the list of movements in the newborn consists of some patterns that cannot be

Table 2: Developmental sequence of fetal behavioral patterns observed by 4D US in the first trimester of pregnancy

\begin{tabular}{|c|c|c|c|c|c|}
\hline & \multicolumn{5}{|c|}{ Postconceptional weeks } \\
\hline Type of movements & 7 & 8 & 9 & 10 & 11 \\
\hline General movement & + & + & + & + & + \\
\hline Startle & & + & + & + & + \\
\hline Stretching & & + & + & + & + \\
\hline Isolated arm movement & & + & + & + & + \\
\hline Isolated leg movement & & + & + & + & + \\
\hline Head rotation & & & + & + & + \\
\hline Head anteflexion & & & + & + & + \\
\hline Head retroflexion & & & + & + & + \\
\hline
\end{tabular}



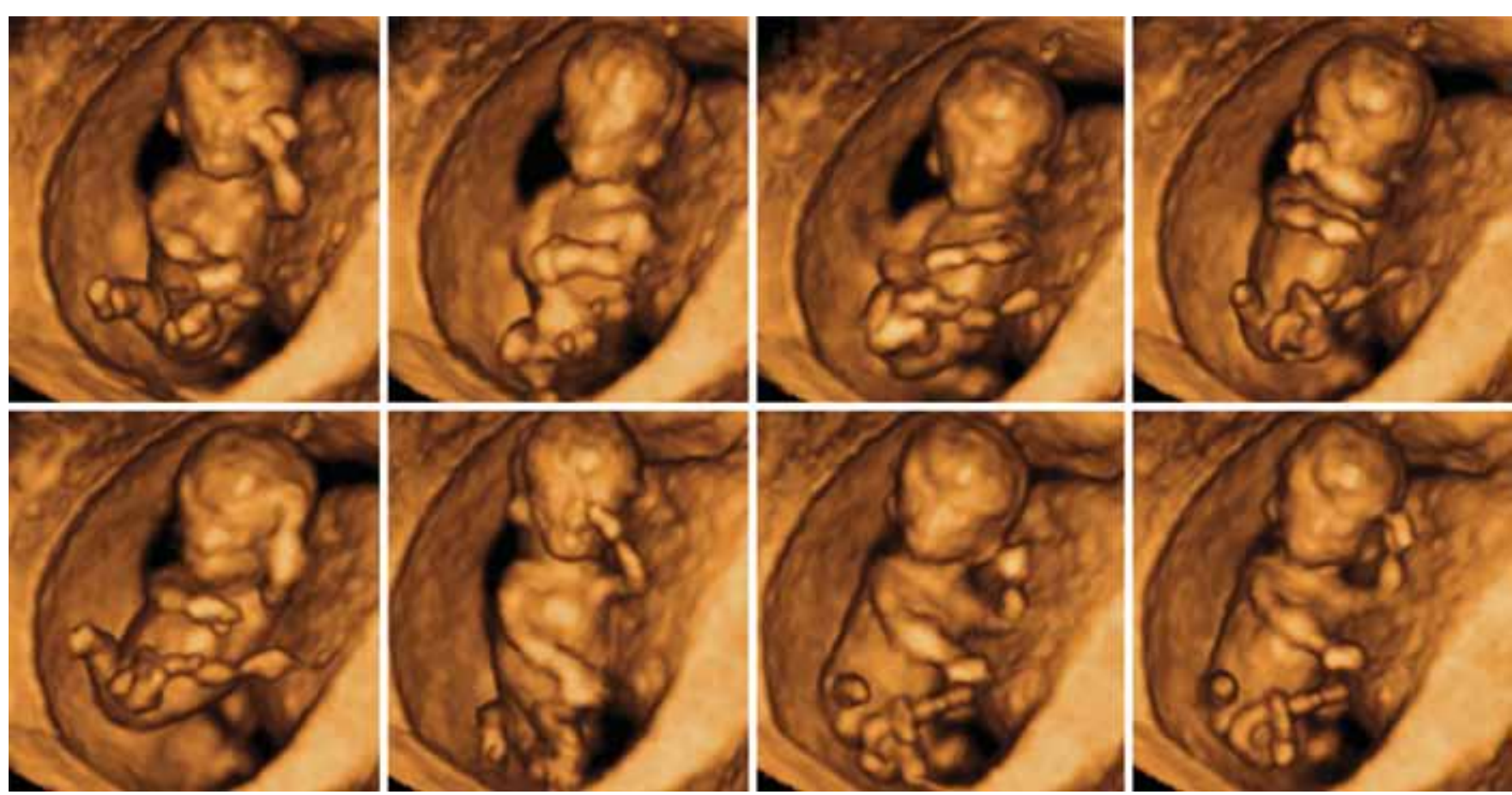

Fig. 1: 4D US imaging demonstrated fetus at 13 weeks of gestation showing general movements pattern

watched in the fetus, such as the Moro reflex..$^{27}$ As well, study of anencephalic fetuses have presented clear evidence for the influence of supraspinal structures on motor behavior at around the 20th gestational week. In these fetuses the number of movements was normal or even increased, but the complexity of the movement patterns distorted radically and movements were stereotyped and simplified..$^{28}$

The eminence of fetal movement patterns is distorted in fetuses undergoing intrauterine growth restriction. The activities become slower and monotonous, similar to cramps and their variability in force and amplitude is reduced. ${ }^{29}$ These changes might designate the subsistence of brain lesions in growth-restricted and possibly hypoxic fetuses. Despite the premature postulations, the changes in the amplitude and complexity of movements in these fetuses do not show to be due to oligohydramnios. In cases of premature rupture of fetal membranes and a subsequently reduced volume of amniotic fluid, movements arise less frequently, but their complexity look likes that of movements achieved in the normal volume of amniotic fluid. ${ }^{16}$ Qualitative including quantitative analysis of fetal movements divulged the consistency of the fetal nervous system, and can be applied for the recognition of different cerebral dysfunctions and probably neuromuscular ailments.

The application of the new technology, 4D US, in the examination of fetal facial movements has revealed the existence of a full range of facial expressions including grimacing, tongue expulsion and eye-lid movements (Fig. 2) similar to emotional expressions in adults..$^{27,30}$
The possibility of studying such subtle movements might open a new area of investigation. ${ }^{31}$

During the first trimester, a tendency toward increased frequency of fetal general movements with increasing gestational age have been noticed (Fig. 3A). While at the beginning of the second trimester, the fetuses began to display a tendency toward increased frequency of observed fetal facial expression up to the end of the second trimester. An oscillation and dispersion of the incidence of the facial expression as seen in the polynomial regression of isolated eye blinking diagram is observable in Figure 3B. ${ }^{30}$

The most frequent facial movement patterns in the second trimester were isolated eye blinking, grimacing, suckling and swallowing, while yawning, mouthing, tongue expulsion and smiling could be observed less frequently. ${ }^{25,30}$ During the third trimester, the fetuses began to display decreasing or stagnant incidence of fetal facial expression. All of the type of head movements and hand to body contact indicated a tendency to decrease frequency from the beginning of the second trimester to the end of the third trimester (Fig. 3C). ${ }^{30}$

The investigations of fetal facial expressions established that all mechanisms of the fetal yawning pattern, prolonged jaw opening followed by a quick closure and accompanied by head flexion and elevation of arms, can easily be documented by $4 \mathrm{D}$ US in this period (Figs 4 to 10$){ }^{32}$ If the fetal yawning in the third trimester was matched up to the yawning in the neonates during the first week of life, no differences were found in the frequencies of this reaction, The frequency of yawning steadily increased between 15 th and 24 th week when a short 

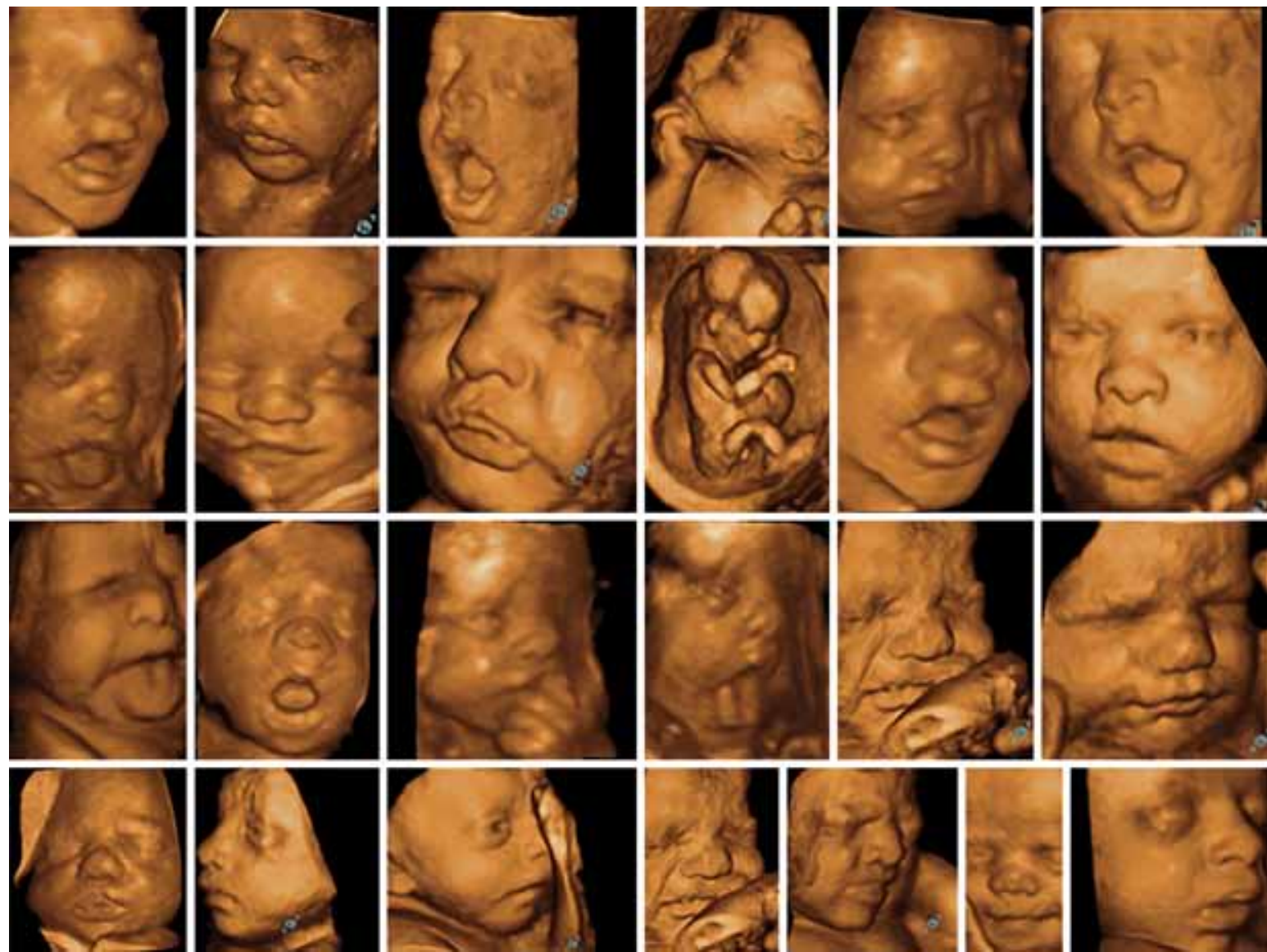

Fig. 2: 3D/4D US provides clear depiction of dynamic changes of fetal facial expression allowing study of fetal behavior during all trimesters of pregnancy
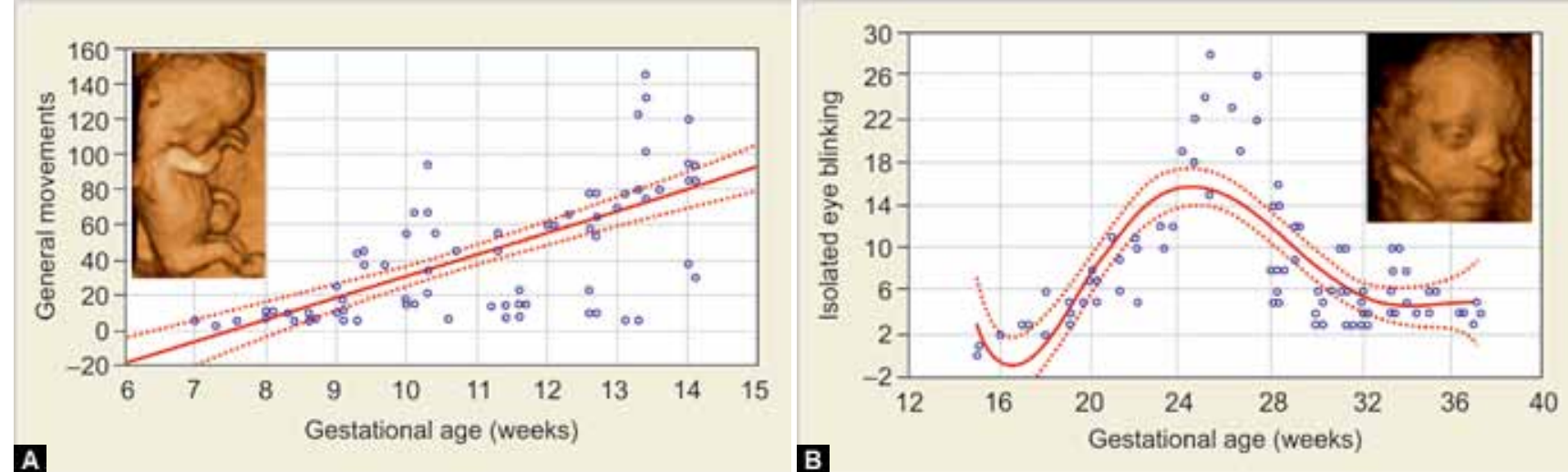

A

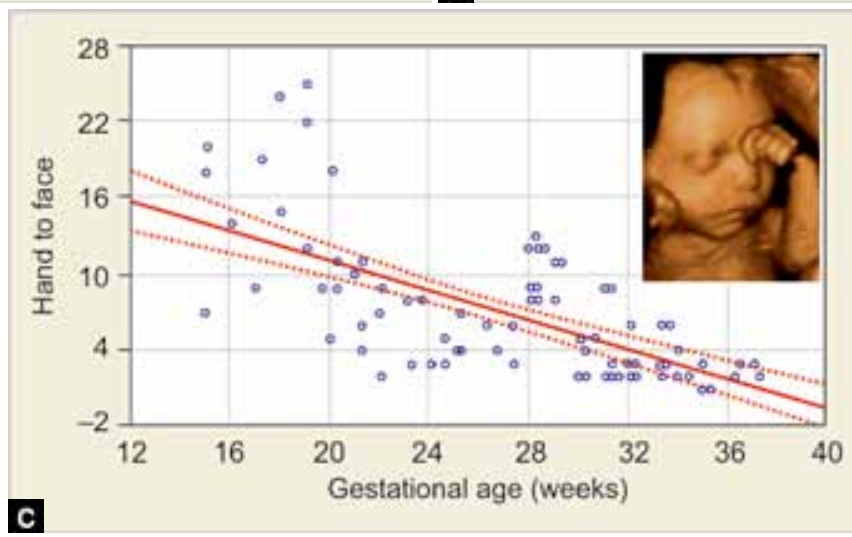

Figs 3A to C: Quantitative analysis of normal fetal behavior patterns using 4D US: (A) General movements,

(B) Isolated eye blinking and $(C)$ Hand to face movement 

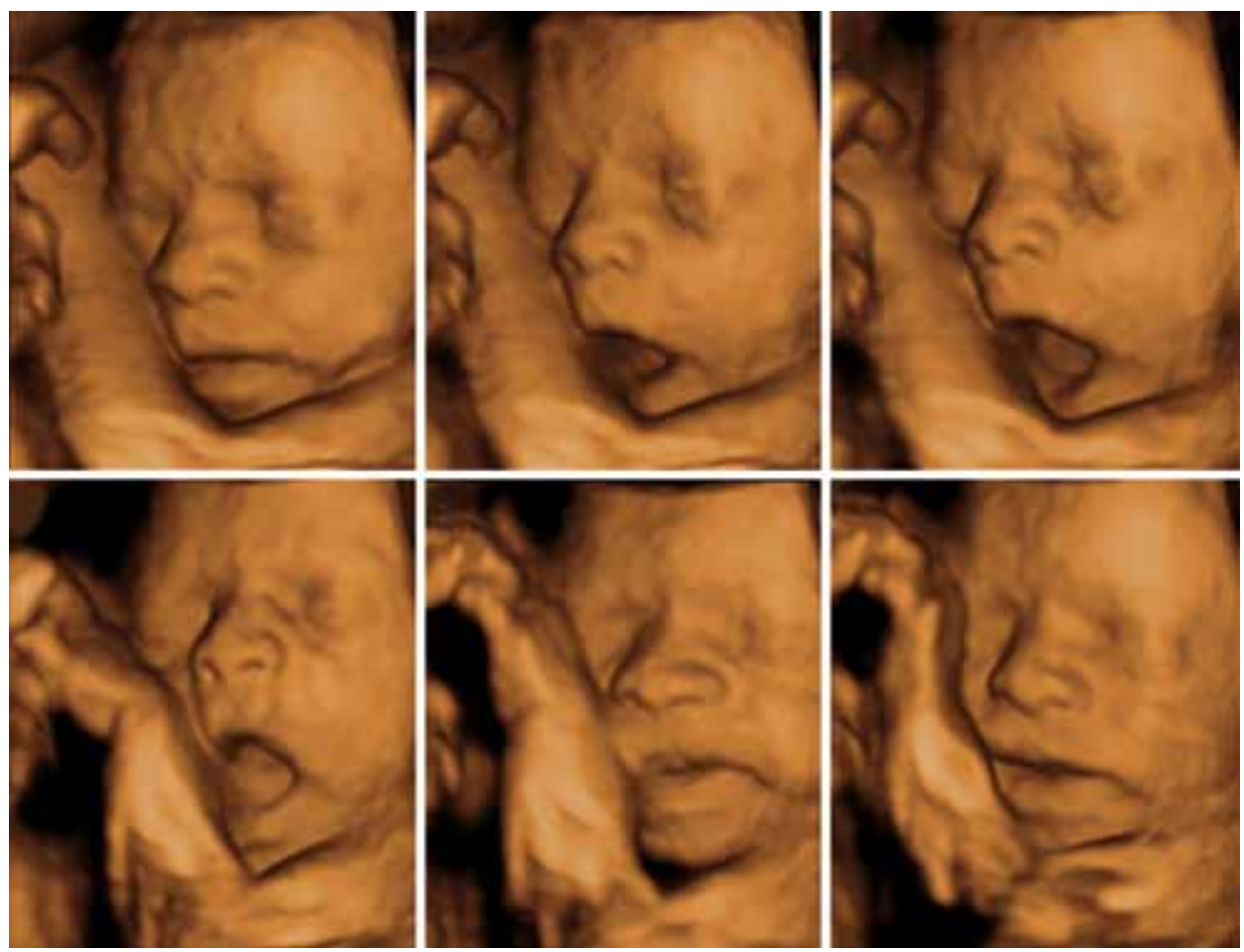

Fig. 4: 4D US image sequences of facial expression characterized by stereotyped yawning opening

plateau was observed from 24th to 26th week and was followed by a slight decrease toward the term. ${ }^{30}$ A gestational age-related tendency in the frequency of yawning could be assumed as the maturation of the brain stem and probably the gaining of control of more cranial structures over yawning pattern. These results have offered new data concerning the route of neurodevelopment of this fascinating, but poorly implicit reflex. Whether this is distorted in cases of neurodevelopmental disorders and whether such adaptations can give us impending into the function of fetal nervous system in high risk pregnancies, continues to be determined. It also stays to be determined to what possibility are the facial motoric patterns related to the function and integrity of the CNS. However, the fact that even in the embryonic stage, the identical inductive forces that cause growth and restyling of the neural tube influence the development of facial structures, and that many genetic disorders affecting the CNS are also described by dysmorphology and dysfunction of facial structures, underline the value of these studies. , $30,31^{2}$

\section{Neonatal Aspect of Fetal Neurology}

Obstetric aspects of fetal neurology have been discussed extensively in our previous publications..$^{19-25,27,28-31}$ In order to better understand fetal neurobehavioral patterns, we have learned a lot form basic studies of brain development and from clinical postnatal studies of neonates. Now, when we have reached the edge of fetal behavioral investigation by $4 \mathrm{D}$ ultrasonography in normal fetuses, we intend to find some new ideas and ways of investigation presenting neonatal aspect of fetal neurology.

Cerebral palsy (CP) is an 'umbrella' term for disorders of development, movement and posture, resulting in limitations of activity due to nonprogressive impairment of developing brain. ${ }^{33}$ The diagnosis of $\mathrm{CP}$ is retrospective and it is exceptionally made before the age of 6 months in only most severely affected infants, and the specificity of the diagnosis will improve as the child ages and the nature of the disability evolves. ${ }^{34} \mathrm{CP}$ does not result from a single event but rather there is a sequence of interdependent adverse events providing to the condition. ${ }^{35}$ This time frame of evolving adverse events is something which should be taken into account when considering the possibility of CP diagnosis in infants. ${ }^{34,35}$ The understanding of the profile of a child's disability across multiple domains is an ongoing process necessary for appropriate treatment and future planning. ${ }^{34}$ This theoretical statement is sometimes very difficult to be practically implemented. An attempt to make early diagnosis of $\mathrm{CP}$ should be followed with factors related to pathogenesis, impairment and functional limitations in every patient. ${ }^{34}$ In order to identify pathogenesis of the process, neuroimaging methods should be used, among which cranial ultrasound, magnetic resonance imaging, magnetic resonance spectroscopy and diffusion weighted imaging are the most frequently used in very low birth-weight premature infants and in term infants with encephalopathy. ${ }^{34}$ Impairment of organs or 
systems by clinical assessment of muscle tone, strength, and control of voluntary movements for early detection of infants with the risk for $\mathrm{CP}$ has been frustrating, because only $43 \%$ of 7 -year-old children with CP had a normal newborn neurological examination. ${ }^{34,36}$ Is it possible to change this discouraging fact resulting form our failure to diagnose neurological impairment early enough to intervene? Interests in diagnosis of neurological impairment among ultrasonographers using 4D ultrasound have been recently shifted toward prenatal period. ${ }^{23,37}$ Is there any possibility to improve timing of postnatal diagnosis of neurologically disabled infant? Postnatal assessment is probably easier to perform than prenatal, by using a simple and suitable for everyday work screening clinical test with good reliability, specificity and sensitivity. Such tests are still not widely used, while those complicated and time consuming are used mostly for clinical research purposes. There is a possibility for the early and simple neurological assessment of the term and preterm newborns with the aim to detect associated risks and anticipate long-term outcome of the infant, and to establish a possible causative link between pregnancy course and neurodevelopmental outcome. ${ }^{38}$ As CP is a disorder of movement and postural control resulting in functional limitations, its diagnosis could be helpful in detection of early impairment. ${ }^{34}$ Clinical neurological assessment proposed and practiced by Amiel-Tison could be very useful in the early detection of newborns at risk. ${ }^{38}$ As development of central nervous system (CNS) is very complex and long-lasting process, the assessment of its developmental optimality is something which should be assessed in order to investigate whether the infant is neurologically normal or damaged. Neurological assessment at term by Amiel-Tison is taking into account neurological maturation exploring so called lower subcortical system developing earlier from the reticular formation, vestibular nuclei and tectum, and upper cortical system developing from the corticospinal pathways. ${ }^{39}$ The role of lower system is to maintain posture against gravity, while the upper system is responsible for the control of erect posture and for the movements of the extremities. ${ }^{39}$ At the corrected age of 40 gestational weeks optimality assessment consists of: head circumference measurement, assessment of cranial sutures, visual pursuit, social interaction, sucking reflex, raise-to-sit and reverse, passive tone in the axis, passive tone in the limbs, fingers and thumbs outside the fist, and autonomic control during assessment. ${ }^{39}$ The Amiel-Tisson neurologic assessment at term is increasing accuracy in assessing CNS function in the neonate by using simple scoring system, focusing on the most meaningful items, promoting a clinical synthesis at term, for term and preterm infants. ${ }^{39}$ It was recognized that clinicoanatomic correlations using high resolution neuroimaging techniques could be helpful in the neurological assessment of newborns, while the neurological examination and the functional assessment of the developing CNS are bringing a new perspective of CNS status in neonatal period. ${ }^{40}$

\section{General Movements}

In the last 30 years, objective assessment of videotaped general movements by Precht's method has been shown to be predictive of later $\mathrm{CP} .{ }^{9,16,18,41}$ The quality of general movements at 2 to 4 months post-term (so-called fidgety GM age) has been found to have highest predictive value in the detection of the infants at risk for CP development. ${ }^{42}$ It seems that assessment of the quality of GM is a window for early detection of children at high risk for developmental disorders. ${ }^{1742}$ Method is simple and it is based on the so called Gestalt evaluation of GM complexity and variation. ${ }^{17,41,42}$ Assessment of GMs at 2 to 4 months post-term at so called fidgety GM age has been found to have the highest predictive value for development of CP if abnormal. ${ }^{17,41,42}$

Heinz Prechtl's work enabled that spontaneous motility during human development has been brought into focus of interest of many perinatologists prenatally and developmental neurologists postnatally. $916,18,41,42$ According to the research preceding Prechtl's ingenious idea, during the development of the individual the functional repertoire of the developing neural structure must meet the requirements of the organism and its environment. ${ }^{41}$ This concept of ontogenetic adaptation fits excellently to the development of human organism, which is during each developmental stage adapted to the internal and external requirements. ${ }^{41}$ Prechtl stated that spontaneous motility, as the expression of spontaneous neural activity, is a marker of brain proper or disturbed function. ${ }^{41,42}$ The observation of unstimulated fetus or infant which is the result of spontaneous behavior without sensory stimulation is the best method to assess its central nervous system capacity. ${ }^{41}$ All endogenously generated movement patterns from unstimulated central nervous system could be observed as early as from the 7 to 8 weeks of postmenstrual age, with developing a reach repertoire of movements within the next 2 or 3 weeks, continuing to be present for 5 to 6 months postnatally. ${ }^{13}$ This remarkable fact of the continuity of endogenously generated activity from prenatal to postnatal life is the great opportunity to find out those high risk fetuses and infants in whom development of neurological impairment is emerging. The most important among those movements are GMs involving the whole body in a variable sequence of arm, leg, neck and trunk movements, 
with gradual beginning and the end. They wax and wane in intensity, force and speed being fluent and elegant with the impression of complexity and variability. GMs are called fetal or preterm from 28 to 36 to 38 weeks of postmenstrual age, while after that we have at least two types of movements: writhing present to 46 to 52 weeks of postmenstrual age and fidgety movements present till 54 to 58 weeks of postmenstrual age. ${ }^{18,41,42}$ Lack of fluency and existence of considerable variation and complexity are the main characteristics of mildly abnormal GMs. ${ }^{43}$ When complexity, variation and fluency are absent, than we are dealing with definitely abnormal GMs. ${ }^{43}$

The quality of each individual movement includes speed, amplitude and force combined in one complex perception. ${ }^{13,18,41-44}$ Investigation of normal and neurologically impaired preterm infants showed that except for higher incidence of cloni in the abnormal group, there was no marked difference in the quantity of different motor patterns studied. ${ }^{44,45}$ However, video analysis of another group of sick preterm infants revealed a 'reduction of elegance and fluency as well as variability, fluctuation in intensity and speed rather than any change in incidence of distinct motor patterns'. ${ }^{4-46}$ Based on postnatal studies, it would be very important to seek for abnormal quantity and quality of prenatal movements in order to find fetuses neurologically at risk. ${ }^{46}$

Some facts are very important in the assessment of GMs. The first is that evaluation of GMs should be based on the video recorded movements either pre- or postnatally. The second fact is that when assessing GMs one should use so called 'gestalt perception', which could be described as overall impression of GMs with standardized procedure. ${ }^{41}$ During the perception one should recognize the movement patterns of GMs, than assess their complexity, variability and fluency. ${ }^{41,42}$ According to Hadders-Algra, GMs could be classified as normal-optimal, normal-suboptimal, mildly abnormal and definitely abnormal. ${ }^{42}$ This modality of GM assessment is important for the prenatal and postnatal observation of GMs. It is not so important to asses the quantity of GMs, while the assessment of their quality is of utmost importance in terms of the prognosis of neurodevelopmental outcome. They can better predict neurodevelopmental outcome than classical neurologic examination alone. ${ }^{47}$

We can conclude that prenatal and postnatal assessment of GMs according to Prechtl's method gives quite new insight on the function and development of central nervous system. This important modality is time consuming and requires some technology and expertise to be practiced, but advantages of its implementation in prenatal and postnatal life are very promising and encouraging in terms of its prognostic value. Prenatal assessment of GMs is well-developed and established, while prenatal assessment needs sophisticated real time 4D ultrasonographic or other technology in order to enable more precise assessment of GM quality in fetuses.

\section{Continuity of GMs from Prenatal to Postnatal Life}

Postnatal studies of neonatal behavior have taught us that the assessment of behavior is a better predictor of neurodevelopment disability than neurological examinations. ${ }^{46}$ It is important to mention that postnatal observation of movement patterns was introduced by Prechtl et al in the way that they have been observing spontaneous movements of the infant using video typing and 'off-line' analysis of both quantity and quality of the movement. ${ }^{17,48}$ They proved that assessment of general movements in high risk newborns has significantly higher predictive value for later neurological development than neurological examination. ${ }^{46,47,49}$ Kurjak et al conducted a study by 4D ultrasound and confirmed earlier findings made by 2D ultrasonography, that there is behavioral pattern continuity from prenatal to postnatal life. ${ }^{27}$ Assessment of neonatal behavior is a better method for early detection of $\mathrm{CP}$ than neurological examination alone. ${ }^{50}$ It is being speculated that intrauterine detection of encephalopathy would improve the outcome. Although, many fetal behavioral studies have been conducted, it is still questionable whether the assessment of continuity from fetal to neonatal behavior could improve our ability of early detection of brain pathology. Early detection could possibly rise an opportunity to intervene and even prevent the expected damage.

\section{Could Some Postnatal Signs of Neurological Disability be used Prenatally?}

It has been proven by now that ultrasonography is a powerful tool in the assessment of fetal behavior. $4 \mathrm{D}$ sonography brought up to light visual observation of the fetus, particularly in two especially important domains: fetal finger movements and facial expressions. ${ }^{19,51}$ This new technology is not only a toll of fetal observation but a very useful toll to evaluate the development of fetal CNS in normally developing fetuses and those at high risk. A basic understanding of fetal neurology includes: defining of motor pathways involved, chronology of their maturation and direction of myelination. ${ }^{52,53}$ This information helps clinician in better interpretation of fetal movements. The experience acquired with the AmielTison's Neurological Assessment at Term (ATNAT) helps us in interpretation of fetal movements. ${ }^{39,54,55}$ 
The domain of fetal neurology is already too extensive, but the focus of interest is mainly second trimester, despite the fact that spontaneous fetal mobility emerges and has already became differentiated at a very early age. ${ }^{56}$ This means that we will take into a consideration period of pregnancy from 20 till 40 weeks of gestation, including the end of the neuronal migration and the postmigratory phase corresponding to the development of neocortex. ${ }^{4,57}$

As it was already mentioned, $\mathrm{CP}$ describes a group of disorders of the development of movement and posture, causing activity limitations, which are attributed to nonprogressive disturbances occurring at the time of fetal brain development. ${ }^{58-61}$ Motor disorders which occur in patients with $\mathrm{CP}$ are often accompanied by disturbances of sensation, cognition, communication, perception, behavior, and/or with seizure disorder. ${ }^{58-61}$ 'Disturbances' is a term that refers to events or processes that in some way influence the expected pattern of brain maturation..$^{55}$ Those events or processes are many, with consequences varying from very conspicuous to very subtle. It should be kept in mind what many neurologists emphasize, that morphology does not always correspond to neurological outcome. . $^{39,54,55}$ The opposite view is the one from pediatricians and neurophysiologists, who are involved in long-term followup studies, and they are certainly not that optimistic. It would be wise to consider long run prognosis, for each specific type of fetal brain damage and make appropriate decisions for conservative management.

Hopes have been headed toward MR, but in many cases brain changes can not be detected as early as the first year of life, like for example pathological gliosis which causes secondary hypomyelination.

While examining the fetal head by $4 \mathrm{D}$, sonographer should examine bony structures and fetal cranial sutures, if they are folding over one another, it is considered to bee a bed sign previously described by Amiel-Tison. ${ }^{39,55}$ The same sign should be searched for postnatally, as a part of neurological examination. ${ }^{62}$

The majority of pediatricians believe that the main obstacle for early prediction of $\mathrm{CP}$ based on a functional observation of the fetus such as visual observation by $4 \mathrm{D}$ sonography, is due to the 'precompetent' stage of most of the motor behavior observed in utero. ${ }^{39,55}$ One of the possible signs detected could be high arched palate, described by Amiel-Tison, in clinical assessment of the infant nervous system. ${ }^{39,55}$ What was believed as undetectable became visible by $4 \mathrm{D}$. Recently, the 3D 'reverse face technique' has been described. This technique overcomes shadowing the fetal face by rotating the frontal facial image through $180^{\circ}$ along the vertical axis, so that the palate, nasal cavity and orbits become visualized. ${ }^{63,64}$
In their early work, Pooh and Ogura examined ${ }^{65}$ normal fetuses by 3D/4D. The purpose of their study was to investigate the natural course of fetal hand and finger positioning. ${ }^{26}$ During 9 th and on the beginning of 10th week fetal hands were located in front of the chest and no movements of wrists and fingers were visualized. From the middle of 10th week, active arm movements were observed. ${ }^{26}$ This study is very important, because it is showing that finger and thumbs movements begun in the early stage of human life, long before the maturation of the upper system. Therefore this motor activity depends on the lower system and not before 30 to 32 weeks switches to the upper control.

Amiel-Tison also described so called neurologic thumb squeezed in a fist. Clenched fingers can also be detected by $4 \mathrm{D}$ sonography, as well as overlaping cerebral sutures. ${ }^{19,26}$

Head anteflexion becomes visible during 10th and 11th gestational week, according to de Vries et al. ${ }^{56}$ However, the activity of flexor muscles will depend on the upper system since 34 weeks of gestation. The absence of active head flexion explored by the raise-to-sit maneuver is one of the major neurological signs at 40 weeks of gestation. $39,54,62$

Indeed, recent advances of technology and especially of three-dimensional (3D) and four-dimensional (4D) ultrasound, have given us the opportunity to study in real time and with explicit detail parts of fetal anatomy and fetal activity, that we could not imagine it would be possible even a few years ago. As we already described, we now know that there is a specific fetal behavioral pattern that corresponds to each week or trimester of fetal life and this pattern reflects the steps of human brain development and maturation. ${ }^{12,66-68}$ It is clear that the development of the human brain is a long lasting procedure that with specific developmental stages, starting from the first few weeks of in utero life and continues long after birth, in such a way that it remains incomplete at the end of in utero life and continues to evolve for decades after birth ${ }^{68}$ (Table 3). Human brain development is also very sensitive and affected by wide variety of factors and defects at any of stage of fetal or neonatal life. For example in neonates born very prematurely the brain development ex utero as much as we try to resemble the intrauterine environment cannot follow the genetically programmed growth pattern that the brain should have in utero. ${ }^{69,70}$ Genetic factors, external stimuli, pathological conditions or even environmental changes, can affect the fetal human brain up to a degree that may be difficult to assess, especially prenatally. Many times we cannot detect fetal brain impairment, and even in cases when we suspect that fetal brain impairment 
Table 3: Major events in neural development

\begin{tabular}{|c|c|}
\hline Developmental event & Peak time of occurrence \\
\hline $\begin{array}{l}\text { Primary neurulation } \\
\text { (dorsal induction) }\end{array}$ & 3-4 weeks antenatally \\
\hline $\begin{array}{l}\text { Prosencephalic cleavage } \\
\text { (ventral induction) }\end{array}$ & 5-6 weeks antenatally \\
\hline $\begin{array}{l}\text { - Neuronal proliferation } \\
-\quad \text { Cerebral } \\
-\quad \text { Cerebellar }\end{array}$ & $\begin{array}{l}2-4 \text { months antenatally } \\
2-10 \text { months postnatally }\end{array}$ \\
\hline $\begin{array}{l}\text { Neuronal migration } \\
-\quad \text { Cerebral } \\
- \text { Cerebellar }\end{array}$ & $\begin{array}{l}3-5 \text { months antenatally } \\
4-10 \text { months antenatally }\end{array}$ \\
\hline $\begin{array}{l}\text { - } \\
-\quad \text { Axon outgrowth } \\
-\quad \text { Dendric growth and } \\
\text { synapse formation }\end{array}$ & $\begin{array}{l}3 \text { months - birth } \\
6 \text { months }-1 \text { year postnatally }\end{array}$ \\
\hline - Synaptic rearrangement & Birth-years postnatally \\
\hline - Myelination & Birth-years postnatally \\
\hline
\end{tabular}

By Kurjak et al Ultrasound Rev Obstet Gynecol 2004

may exist, in most cases we are unable to clarify how will the fetus be affected. Neurological compromises may occur prenatally, perinatally and/or even postnatally or neonatally, and their clinical picture, varies ranging from mild behavioral and learning disabilities to severe cerebral palsy (CP).$^{68}$ Indeed, neurological disability is one of the most feared complications in obstetrics and its diagnosis antenatally is one of the greatest challenges. The assessment fetal neurobehavior both in normal and abnormal cases is a major project, since first of all we need to study and understand the normal cases before we can compare them with the pathological ones in order to draws safe conclusions. ${ }^{70,71}$

\section{CAN WE ASSESS FETAL BEHAVIOR WITH ULTRASOUND?}

We know that fetal behavioral patterns reflect the degree of development and maturation of the fetal nervous system, and it has also been proved that the quality and quantity of fetal movements reflect the neurological integrity of the fetus. ${ }^{1,48,72-79}$ The introduction of two dimensional ultrasound allowed the assessment of fetal anatomy, but also the direct monitoring of fetal activity. ${ }^{18}$ Fetal movements were studied and analyzed with 2D even 30 years ago, $18,80-82$ and further studies suggested that the assessment of fetal behavior in the specific periods of in utero life could make it possible to distinguish between normal and abnormal brain developmental patterns. ${ }^{50,82-84}$ Advances in ultrasound technology introduced 3D and 4D ultrasound, offering exceptional images of the fetus in utero and in real time, allowing to evaluate even the movements and the behavior of the fetus in utero, overcoming the problem of subjective poorer quality images obtained with 2D ultrasound. ${ }^{84-88}$ 4 D ultrasound allows imaging of details of fetal face and fetal expressions (e.g. smiling, crying, mouthing and blinking), something that cannot be achieved with 2D ultrasound. Studies have shown that with $4 \mathrm{D}$ ultrasound it is feasible to distinguish between normal and abnormal behavioral patterns of the fetus, which could eventually lead to early diagnosis of brain impairment, enabling us to produce measurable parameters for the assessment of normal neurobehavioral development. ${ }^{20,89-91}$

Fetal movements occur much earlier than when pregnant women can feel them, even during the embryonic period starting with gross, a synchronized movements of the whole embryo and finally leading to organized and detailed movements, as well as facial expressions towards the end of the pregnancy. ${ }^{92,93}$ Regarding neonates the assessment of neonatal behavior is a better predictor of neurodevelopmental disability than neurological examination. So, the question would be whether by studying fetal behavior we could identify cases of normal and abnormal brain development, and also whether we could achieve earlier diagnosis of various structural or functional abnormalities of the fetal nervous system. ${ }^{12,18,50,66-68,80-83,109}$ The first structured and systematic way for assessing the integrity of the fetal central nervous system, by using 4D ultrasound, was called KANET, and its innovation is that it assesses the fetus in utero in the same way that neonates are examined postnatally for brain damage, incorporating parameters from neonatal neurological tests (Amiel-Tison), with the use of $4 \mathrm{D}$ ultrasound. ${ }^{37,38,94,95}$

\section{WHAT IS KURJAK'S ANTENATAL NEURO- DEVELOPMENTAL TEST (KANET)?}

Kurjak's antenatal neurobehavioral test (KANET) is a new scoring system for the assessment of fetal neurobehavior based on prenatal evaluation of the fetus by $3 \mathrm{D} / 4 \mathrm{D}$ ultrasound. ${ }^{94}$ It is a combination of some parameters consisting of fetal general movements (GM) and of postnatal Amiel-Tison neurological assessment at term (ATNAT) signs, which can be easily visualized prenatally by using $4 \mathrm{D}$ ultrasound. ${ }^{25,38}$ The following parameters have been incorporated in the KANET test: isolated head anteflexion, overlapping cranial sutures, head circumference, isolated eye blinking, facial alterations, mouth opening (yawning or mouthing), isolated hand and leg movements and thumb position, Gestalt perception of general movements (overall perception of the body and limb movements with their qualitative assessment).

Several papers have shown that there is a continuity of behavior from pre- to postnatal life and it has been observed that all movements which are present in 
neonates are also present in fetal life, with the exception of Moro's reflex, which cannot be demonstrated in fetuses. ${ }^{96}$ This is probably due to a different environment to which fetus and neonate are exposed. The fetus lives in an environment of microgravity, while the newborn is exposed to full gravity, which creates certain obstacles for neurodevelopment in the first months of life. ${ }^{70}$ The parameters were chosen based on developmental approach to the neurological assessment and on the theory of central pattern generators of general movements emergence, and were the product of multicentric studies conducted for several years. ${ }^{25,30}$ KANET is a combination of assessments of fetal behavior, general movements and three out of four signs which have been postnatally considered as symptoms of possible neurodevelopmental impairment (neurological thumb, overlapping sutures and small head circumference). ${ }^{97}$

KANET test has been standardized, it is reproducible and easily applied by fetal medicine specialists. ${ }^{97}$ KANET should be performed in the 3rd trimester of pregnancy, between 28 and 38 weeks. The duration of the examination should last between 15 and 20 minutes, and fetuses should be examined while they are awake. If the fetus is in the sleeping period, the assessment should be postponed for 30 minutes or for the following day, at a minimum period of 14 to 16 hours. In cases of grossly abnormal or of borderline score, the test should be repeated every 2 weeks until delivery. Special attention should be paid
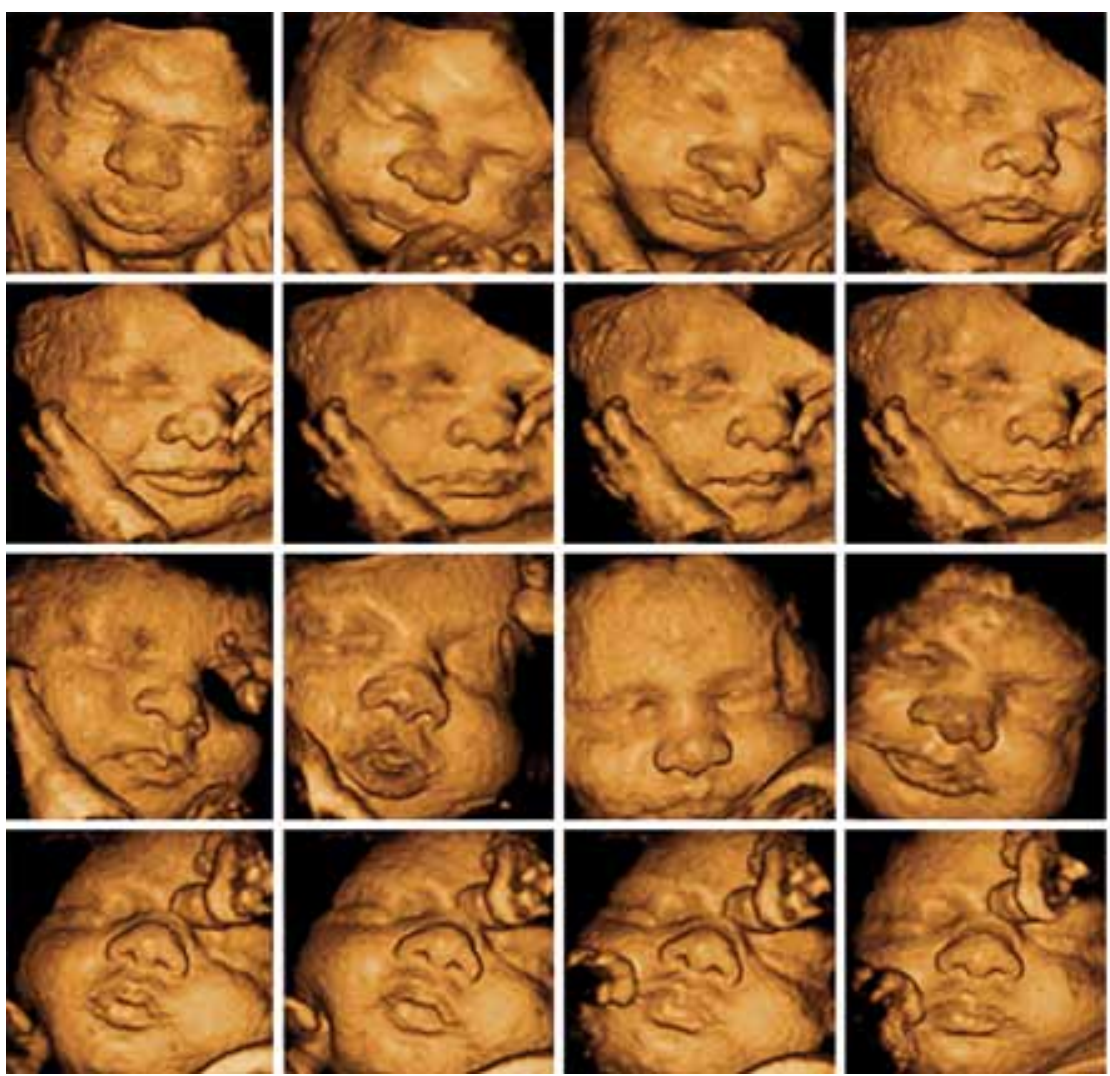

Fig. 5A: Normal KANET score at 34 weeks of pregnancy
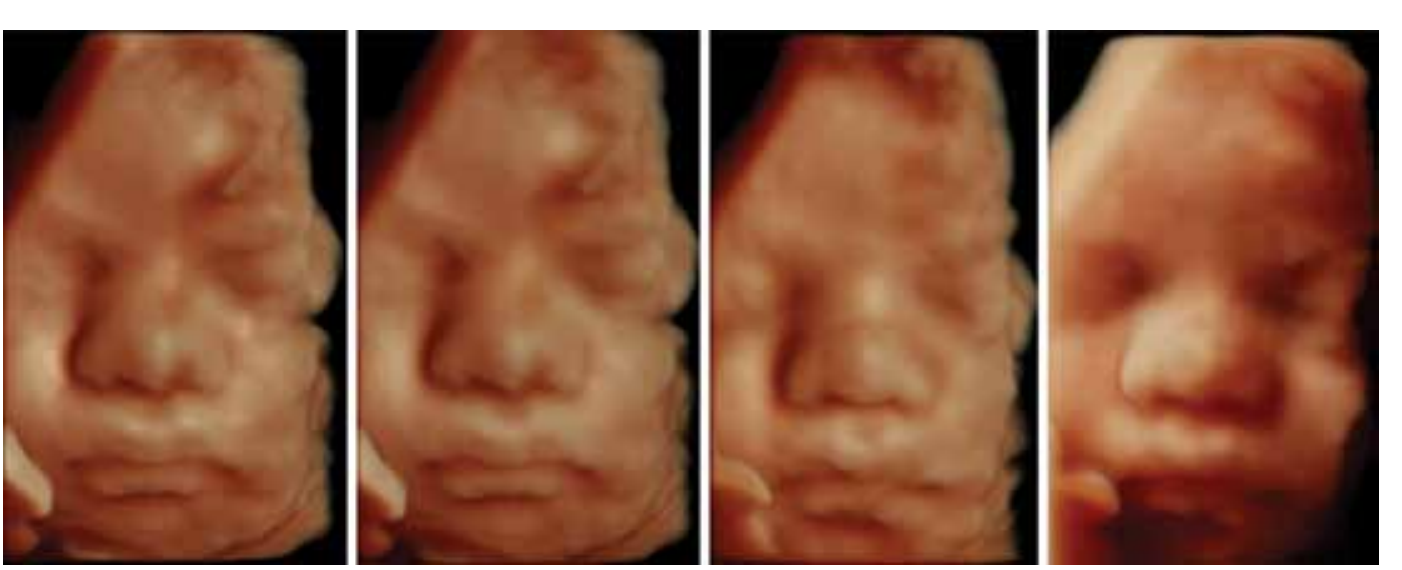

Fig. 5B: Normal KANET score at 32 weeks of pregnancy-the impact of the evolution of ultrasound technology on the quality of fetal assessment

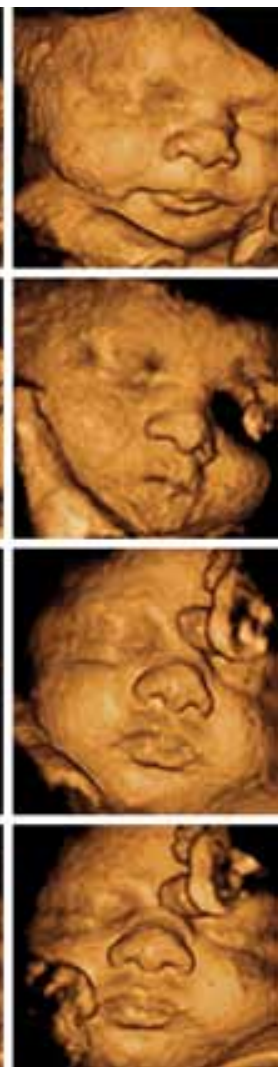



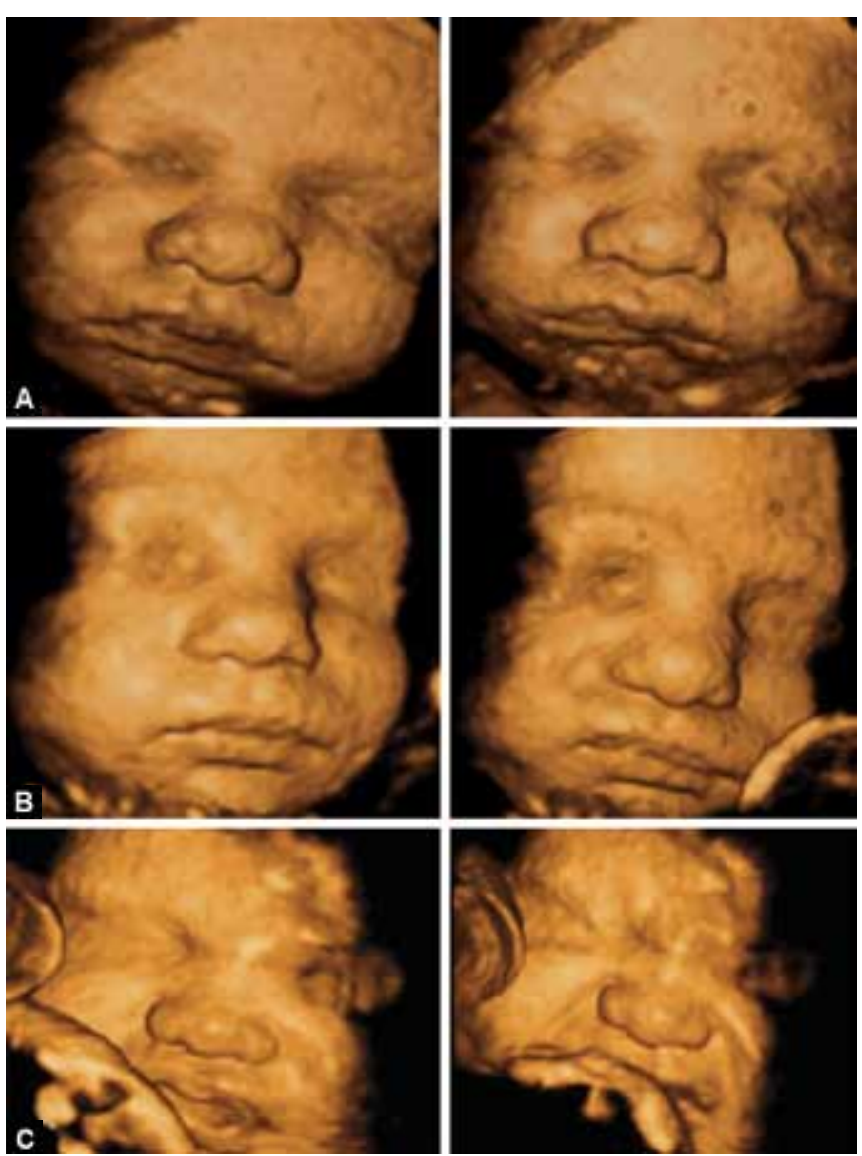

Figs $6 \mathrm{~A}$ to $\mathrm{C}$ : Face grimacing

to the facial movements and to eye blinking, which are prenatally very informative and important ('the face is the mirror of the brain'). Overall number of movements should be defined in very active or inactive fetuses and compared with normal values of previous studies ${ }^{25,30}$ (Figs 5 and 6). All the examiners should have extensive hands-on education for the application of KANET test, both in low and in high-risk pregnancies. Interobserver and intraobservere variability should be available. It is advisable to use $4 \mathrm{D}$ ultrasound machines, with frame rate of minimum 24 volumes/second. KANET consists of eight parameters (Table 4). A score range of 0 to 5 is characterized as abnormal, a score calculated from 6 to 13 is considered borderline and a score range of 14 to 20 is normal (Table 5). After that neonates should be followed up postnatally for neurological development for a 2 years period.

The test evaluates quantitative as well as qualitative aspects of fetal motor behavioral patterns. The parameters examined by this test are a combination of general movements (GMs) and parameters adopted from ATNAT. ${ }^{98,99}$ The criterion of quality and quantity of spontaneous GMs is believed to have excellent reliability in evaluating the integrity of fetal CNS ${ }^{83,100}$ Furthermore a continuity of behavioral patterns from prenatal to the postnatal period has been proven. ${ }^{27,101,102}$ Both those facts justify the choice of the parameters used in this test, making KANET theoretically appropriate for the assessment of fetal behavior. According to previous reports ${ }^{28,29,103-106}$ KANET easily recognizes serious functional impairment associated with structural abnormalities. Studies have shown that application of KANET in both low and high risk populations has given good results and especially in high risk populations, KANET may provide useful information regarding the neurological outcome of these fetuses. ${ }^{107}$ KANET is the first test which is based on 4D ultrasound, with an original scoring system and has been standardized, so it can be implemented in everyday practice, overcoming the practical difficulties and covering the gaps of methods that were used in the past for the evaluation of fetal behavior. ${ }^{16,108-110}$ Studies show that KANET is easily applicable to most pregnancies, the learning curve is reasonable for physicians who already have training in obstetrical ultrasound and the actual duration of KANET ranges from 15 to 20 minutes, showing strong evidence that it can be widely implemented in everyday clinical practice. ${ }^{106}$

\section{WHAT HAVE STUDIES ABOUT KANET SHOWN SO FAR?}

One of the first studies to use a preliminary form of the KANET scoring system was that by Andonotopo et al in 2006. They aimed to assess fetal facial expression and quality of body movements and examine if they are of diagnostic value for brain impairment in fetuses with growth restriction. In that prospective study of 50 pregnancies with IUGR fetuses in the 3rd trimester of pregnancy, a tendency of less behavioral activity in IUGR than normal fetuses has been noted. The results of the study encouraged future investigation of the use of $4 \mathrm{D}$ ultrasound for quantitative and qualitative assessment of fetal behavior as possible indicators of the neurological condition in IUGR fetuses. ${ }^{29}$

The Zagreb group in 2008, were the first to introduce the KANET for the assessment of neurological status of the fetus, aiming to the detection of fetal brain and neurodevelopmental alterations due to in utero brain impairment. In order to develop the new scoring system they identified severely brain damaged neonates and neonates with good neurological condition and then compared the neonatal findings, with corresponding findings in utero. In the group of 100 low-risk pregnancies they retrospectively applied KANET. After delivery, postnatal neurological assessment ATNAT was performed and all neonates assessed as normal reached a score between 14 and 20, which was assumed to be the score of optimal neurological development. New scoring system was applied in the group of 120 high-risk pregnancies in 
Table 4: Proposal for the new KANET assessment tool consisting of eight parameters

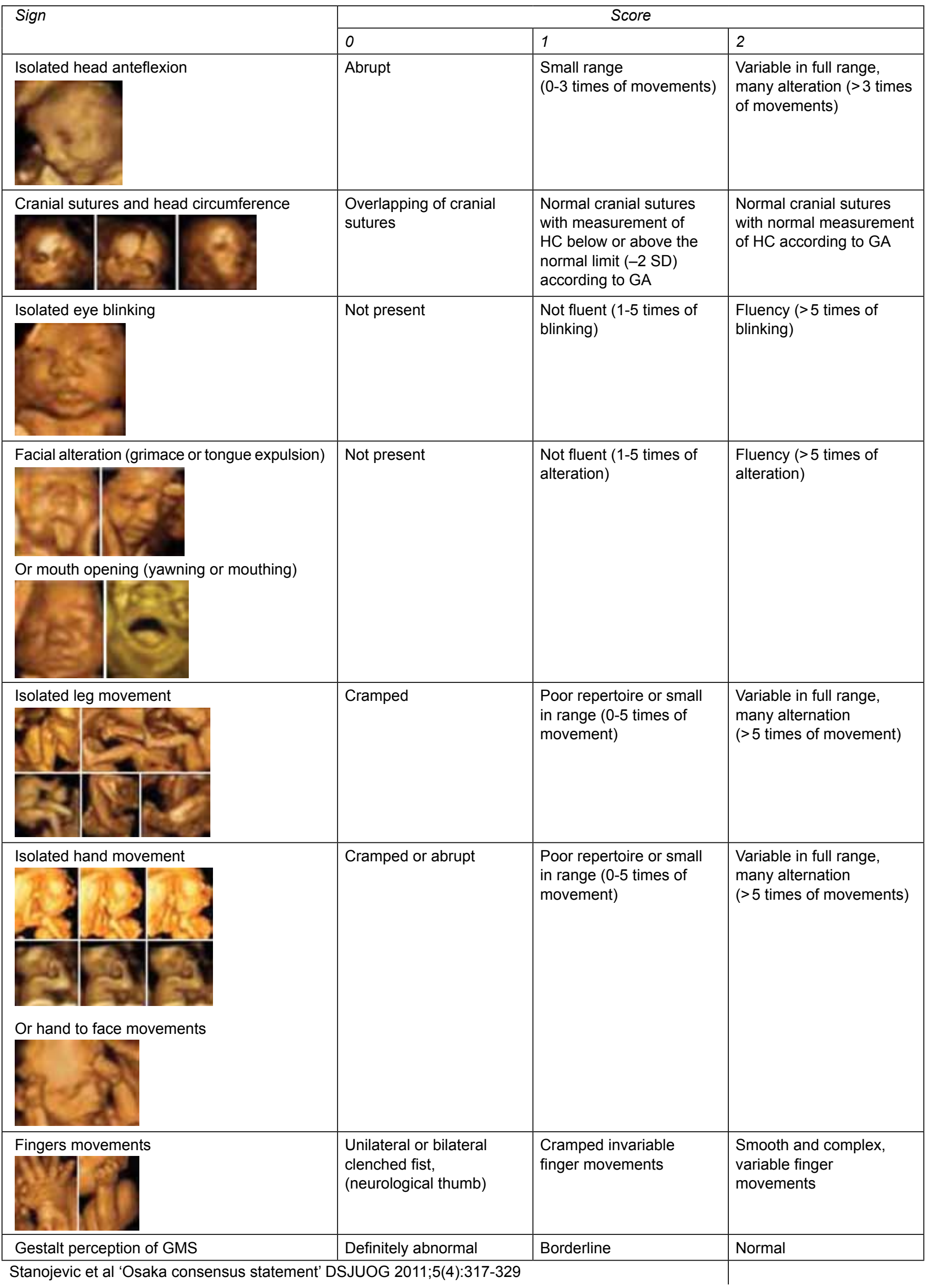


Table 5: Interpretation of KANET scores

\begin{tabular}{ll}
\hline Total score & Interpretation \\
\hline $0-5$ & Abnormal \\
$6-9$ & Borderline \\
$10-16$ & Normal \\
\hline
\end{tabular}

Stanojevic et al 'Osaka consensus statement' DSJUOG 2011;5(4):317-329

which, based on postnatal neurological findings, three subgroups of newborns were identified: normal, mildly or moderately abnormal and abnormal. Based on this, a neurological scoring system has been proposed. All normal fetuses reached a score from 14 to 20. Ten fetuses who were postnatally described as mildly or moderately abnormal achieved a prenatal score of 5 to 13, while another ten fetuses postnatally assigned as neurologically abnormal had a prenatal score 0-5. Among this group four had alobar holoprosencephaly, one had severe hypertensive hydrocephaly, one had thanatophoric dysplasia and four fetuses had multiple malformations. This study inspired a large series of multicenter studies (Table 6) that used the KANET in order to assess the usefulness of this promising new scoring system for the assessment of neurological status in fetuses and the recognition of signs of early brain impairment in utero. ${ }^{85,91}$

The results of the first multicenter study, which included 288 high risk pregnancies, from four different centers, were published in 2010. They identified seven cases with abnormal KANET and twenty five cases with borderline KANET score, yielding 32 fetuses at neurological risk. There were also 11 cases with abnormal KANET, of which 6 fetuses died in utero and 5 were terminated. The seven remaining neonates with abnormal KANET were followed up postnatally at 10 weeks and out of these seven cases, three were found to have abnormal ATNAT scoring postnatally. These were a case of arthrogryposis, a case of vermis aplasia and a fetus whose previous sibling had verified cerebral palsy. The fetuses in these three cases had especially reduced facial movements - the faces were like masks during the ultrasounds. The remaining four cases were considered normal (ventriculomegaly, pre-eclampsia, thrombophilia, oligohydramnios). Out of 25 borderline KANET there were 22 borderline newborns by ATNAT, whereas three were normal (ventriculomegaly, syndrome of intraamniotic infection, maternal thrombocytopenia). Those who were abnormal prenatally and normal postnatally had the following prenatal risk-factors: ventriculomegaly, Dandy-Walker malformation, skeletal dysplasia, polyhydramnios, gestational diabetes, hydrocephaly, thrombophilia, pre-eclampsia, achondroplasia, oligohydramnios, non-immune hydrops, intra-amniotic infection, IUGR, trisomy 21, thrombocytopenia. Out of three abnormal neonates, neonates after ATNAT assessment two had definitely abnormal Prechtl's premature GMs (arthrogryposis and vermis aplasia) and an additional six were considered abnormal (neonate of the mother with the previous child with CP, Dandy-Walker syndrome, hydrocephaly, trisomy 21, ventriculomegaly, non-immune hydrops). The remaining 21 children had normal optimal or normal suboptimal GMs. During their study they also followed the pregnancy of a fetus with acrania, which the mother had refused to terminate due to religious reasons, documenting the evolution of the fetal behavior from 20 weeks and as the motor control was shifting from the lower to the upper control center the fetus ended up with a very low KANET score. The authors reached the conclusion that there is a potential for antenatal detection of serious neurological conditions, especially in identifying the fetuses from high-risk pregnancies at neurological risk. ${ }^{103}$

Miskovic et al applied KANET in 226 cases, both high and low risk pregnancies and compared the results. They found three cases of abnormal KANET, that had chromosomal abnormalities and all three had abnormal ATNAT, as well. The KANET scores from both groups were compared to the results of the ATNAT tests, and found statistically significant difference among the low and the high risk groups, for eight out of the ten KANET parameters (isolated anteflexion of the head, eye blinking, facial expressions - grimacing, tongue expulsion, mouth movement such as yawning, jawing, swallowing - isolated hand movements, hand to face movements, fist and finger movements and general movements). Comparison of KANET and ATNAT showed statistically significant, moderate correlation between the two tests, which means that the neuropediatric exam ATNAT confirmed the prenatal findings of $4 \mathrm{D}$ ultrasound examination KANET. The authors concluded that these preliminary results were promising and stated that further studies are needed before the test could be recommended for wider clinical practice. ${ }^{106}$

Talic et al around the same period, in a multicenter study, published the largest series of KANET so far, with 620 singleton pregnancies, both low- and high-risk cases (100 low risk and 520 high risk cases), excluding however fetuses with structural abnormalities, that were studied between 26 and 38 weeks of gestation. Fetuses with congenital anomalies multiple pregnancies were excluded from the study. The high-risk group of patients consisted of the following subgroups: threatened preterm delivery with or without preterm rupture of membranes (PPROM), previous child diagnosed with $\mathrm{CP}$, hypertension in pregnancy with or without pre-eclampsia, diabetes before pregnancy or gestational diabetes, intrauterine growth restriction, polyhydramnios, Rhesus isoimmunization, placental bleeding and maternal fever $>39^{\circ} \mathrm{C}$. Analysis 
Table 6: List of studies that have applied KANET test to different populations

\begin{tabular}{|c|c|c|c|c|c|c|c|c|c|c|}
\hline Author & Year & Study & $\begin{array}{l}\text { Study } \\
\text { design }\end{array}$ & $\begin{array}{l}\text { Study } \\
\text { population }\end{array}$ & Indication & No & $\begin{array}{l}G A \\
\text { (weeks) }\end{array}$ & $\begin{array}{l}\text { Time } \\
\text { (mins) }\end{array}$ & Result & Summary \\
\hline $\begin{array}{l}\text { Kurjak } \\
\text { et al }{ }^{109}\end{array}$ & 2008 & Cohort & $\begin{array}{l}\text { Retro- } \\
\text { spective }\end{array}$ & High-risk & Multiple & 220 & $20-36$ & 30 & Positive & $\begin{array}{l}\text { A new scoring system was } \\
\text { proposed for the antenatal } \\
\text { assessment of fetal } \\
\text { neurological status }\end{array}$ \\
\hline $\begin{array}{l}\text { Kurjak } \\
\text { et al }{ }^{103}\end{array}$ & 2010 & $\begin{array}{l}\text { Multi- } \\
\text { center }\end{array}$ & Prospective & High-risk & Multiple & 288 & $20-38$ & 30 & Positive & $\begin{array}{l}\text { KANET appeared } \\
\text { to be prognostic of } \\
\text { antenatal detection of } \\
\text { serious neurological } \\
\text { fetal problems. KANET } \\
\text { also identified fetuses } \\
\text { with severe structural } \\
\text { abnormalities, especially } \\
\text { associated with brain } \\
\text { impairment }\end{array}$ \\
\hline $\begin{array}{l}\text { Miskovic } \\
\text { et al }\end{array}$ & 2010 & Cohort & Prospective & High-risk & Multiple & 226 & $20-36$ & 30 & Positive & $\begin{array}{l}\text { Correlation between } \\
\text { antenatal (KANET) and } \\
\text { postnatal (ATNAT) results } \\
\text { was found. KANET } \\
\text { showed differences of fetal } \\
\text { behavior between high } \\
\text { and low-risk pregnancies }\end{array}$ \\
\hline $\begin{array}{l}\text { Talic } \\
\text { et al }^{105}\end{array}$ & 2011 & $\begin{array}{l}\text { Multi- } \\
\text { center } \\
\text { cohort }\end{array}$ & Prospective & High-risk & Multiple & 620 & $26-38$ & $15-20$ & Positive & $\begin{array}{l}\text { KANET test had a } \\
\text { prognostic value in } \\
\text { discriminating normal from } \\
\text { borderline and abnormal } \\
\text { fetal behavior, in normal } \\
\text { and in high-risk cases. } \\
\text { Abnormal KANET scores } \\
\text { were predictable of both } \\
\text { intrauterine and postnatal } \\
\text { death }\end{array}$ \\
\hline $\begin{array}{l}\text { Talic } \\
\text { et al }^{107}\end{array}$ & 2011 & $\begin{array}{l}\text { Multi- } \\
\text { center } \\
\text { cohort }\end{array}$ & Prospective & High-risk & $\begin{array}{l}\text { Ventricu- } \\
\text { lomegaly }\end{array}$ & 240 & $32-36$ & $10-15$ & Positive & $\begin{array}{l}\text { Statistically significant } \\
\text { difference was identified } \\
\text { in KANET scores between } \\
\text { normal pregnancies } \\
\text { and pregnancies with } \\
\text { ventriculomegaly. } \\
\text { Abnormal KANET } \\
\text { scores and most of the } \\
\text { borderline-scores were } \\
\text { noted in fetuses with } \\
\text { severe ventriculomegaly, } \\
\text { especially associated with } \\
\text { additional abnormalities }\end{array}$ \\
\hline $\begin{array}{l}\text { Honemeyer } \\
\text { et al }{ }^{111}\end{array}$ & 2011 & Cohort & Prospective & Unselected & $\begin{array}{l}\text { Unselec- } \\
\text { ted }\end{array}$ & 100 & $28-38$ & $\mathrm{~N} / \mathrm{A}$ & Positive & $\begin{array}{l}\text { Normal prenatal KANET } \\
\text { scores had a significant } \\
\text { predictive value of } \\
\text { a normal postnatal } \\
\text { neurological evaluation }\end{array}$ \\
\hline $\begin{array}{l}\text { Lebit } \\
\text { et al }{ }^{87}\end{array}$ & 2011 & Cohort & Prospective & Low-risk & $\begin{array}{l}\text { Normal } \\
2 \mathrm{D} \\
\text { exami- } \\
\text { nation }\end{array}$ & 144 & $7-38$ & $15-20$ & Positive & $\begin{array}{l}\text { A specific pattern of } \\
\text { fetal neurobehavior } \\
\text { corresponding to each } \\
\text { trimester of pregnancy } \\
\text { was identified }\end{array}$ \\
\hline $\begin{array}{l}\text { Abo-Yaqoub } \\
\text { et al }\end{array}$ & 2012 & Cohort & Prospective & High-risk & Multiple & 80 & $20-38$ & $15-20$ & Positive & $\begin{array}{l}\text { Significant difference in } \\
\text { KANET scores was noted. } \\
\text { All antenatally abnormal } \\
\text { KANET scores had also } \\
\text { an abnormal postnatal } \\
\text { neurological assessment }\end{array}$ \\
\hline
\end{tabular}


Contd...

Vladareanu 2012 Cohort Prospective High-risk Multiple $196 \quad 24-38 \quad$ N/A Positive Most fetuses with normal

et al ${ }^{112}$

Prospective High-risk

Honemeyer 2012 Cohort et $\mathrm{al}^{113}$

2013 Cohort

Kurjak

et $\mathrm{al}^{123}$

Predojevic

et $\mathrm{al}^{124}$

2013 Case

study
Prospective High and

low-risk

Prospective High and

low-risk
Multiple

869

$928-38$

20

Prospective High-risk IUGR

$31-39$

30

Athanasiadis 2013 Cohort et al $^{125}$
Prospective Unselected Multiple (High and (IUGR, low-risk)

152 2nd

and 3rd

trimester

KANET $\rightarrow$ low-risk, those

with borderline $\rightarrow$ IUGR

fetuses with increased

MCA RI and most fetuses

with abnormal KANET

$\rightarrow$ threatened PTD with

PPROM. Difference in fetal

movements was identified

between the 2 groups. For

normal pregnancies $\rightarrow$

$93.4 \%$ of fetuses achieved normal score, for high-risk pregnancies $\rightarrow 78.5 \%$ of fetuses had a normal score

Introduction of the max average KANET score $\rightarrow$ combination of the mean value of KANET scores throughout pregnancy. Revealed a relationship of fetal diurnal rhythm with the pregnancy risk

Statistically significant differences in the distribution of normal, abnormal, and borderline KANET scores between low-risk and high-risk groups were found. Fetal behavior was significantly different between the normal group and the high-risk subgroups

Positive KANET could recognize pathologic and borderline behavior in IUGR fetuses with or without blood flow redistribution. Combined assessment of hemodynamic and motoric parameters could enable in better diagnosis and consultation

N/A Positive The neurodevelopmental score was statistically significant higher in the lowrisk group compared to the high-risk group $(p<0.0004)$. The diabetes subgroup score was statistically significantly higher compared to the IUGR and the pre-eclampsia subgroup $(p=0.0001)$

KANET: Kurjak's antenatal neurological test; No: Number of patients; IUGR: Intrauterine growth restriction; MCA: Middle cerebral artery; PTD: Preterm delivery; PPROM: Preterm premature rupture of membranes; PET: Pre-eclampsia; GDM: Gestational diabetes mellitus

of the data confirmed statistically significant difference in the distribution of fetal KANET scores between the two populations. Impressively the largest incidence of fetuses with abnormal KANET was noticed in the subgroup of participants with a previous child diagnosed with cerebral palsy $(23.8 \%)$ and the largest incidence of fetuses with borderline KANET was observed in the subgroup of mothers with fever $(56.4 \%)$. The following parameters of KANET test significantly differed between the fetuses from low and high-risk pregnancies: 

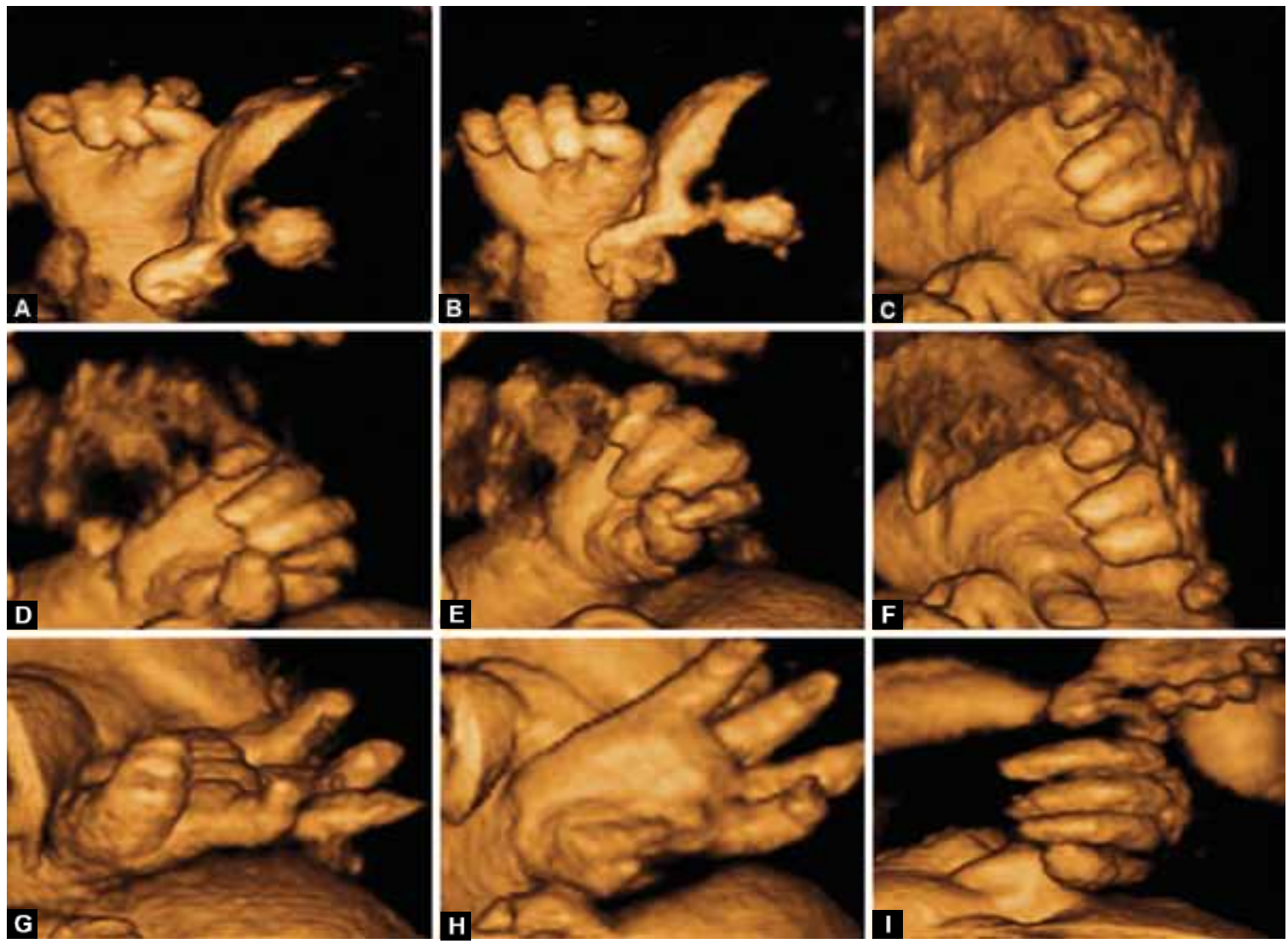

Figs 7A to I: Hand and finger movement
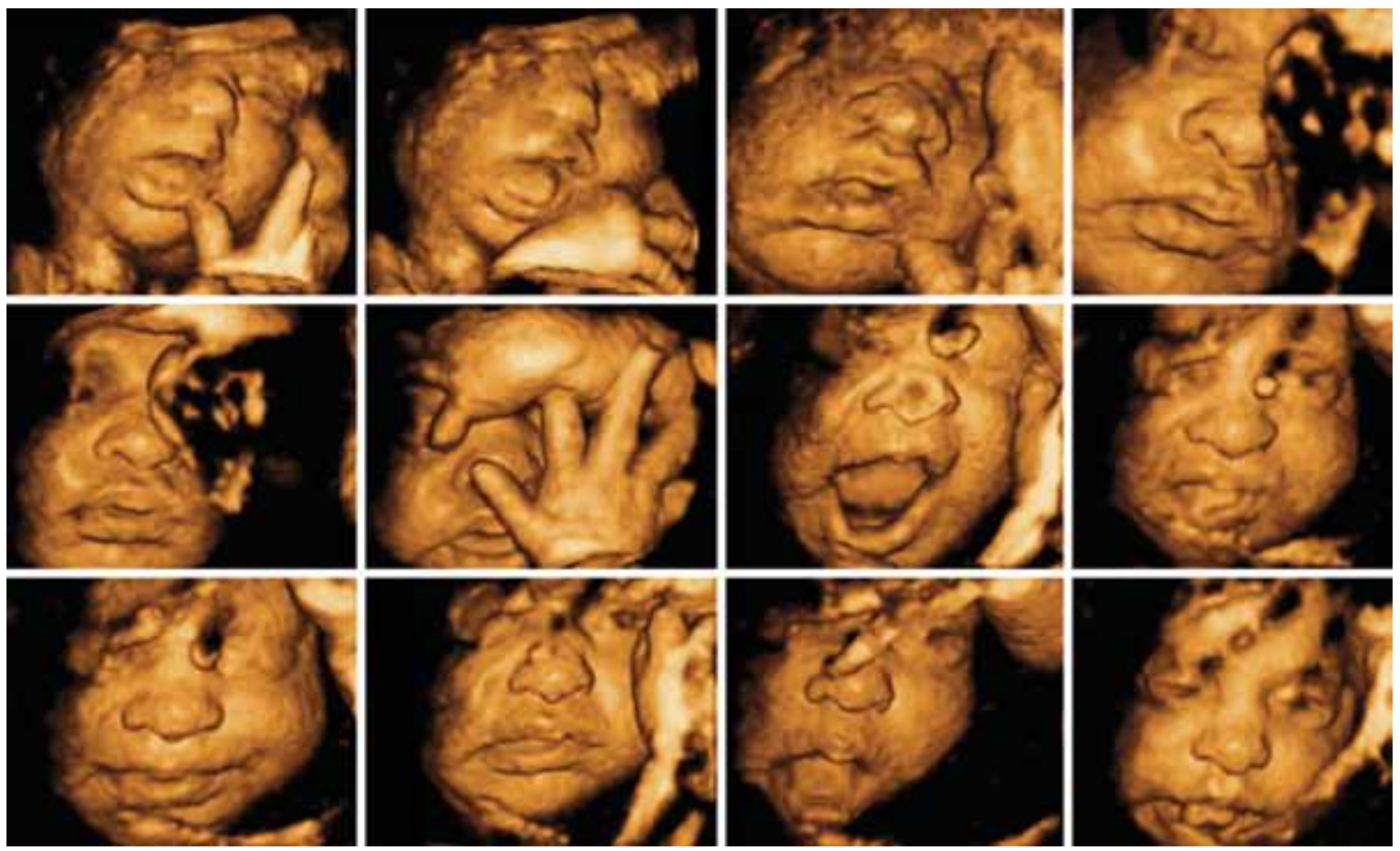

Fig. 8: KANET_facial alterations mouthing, eye blinking and hand movement

overlapping cranial sutures, head circumference, isolated eye blinking, facial expressions, mouth movements, isolated hand movements, isolated leg movements, hand to face movements, finger movements and general movements. The authors observed that a low KANET score is predictive of both intrauterine or neonatal death
- they had two intrauterine deaths in fetuses with low KANET (scores of 3 and 4 respectively) and one neonatal death (with a KANET score of 2). In 10 out of 36 fetuses with abnormal KANET after 2 and 6 months, postnatal neurological examination indicated severely abnormal finding: four of them had severe generalized spasticity. 

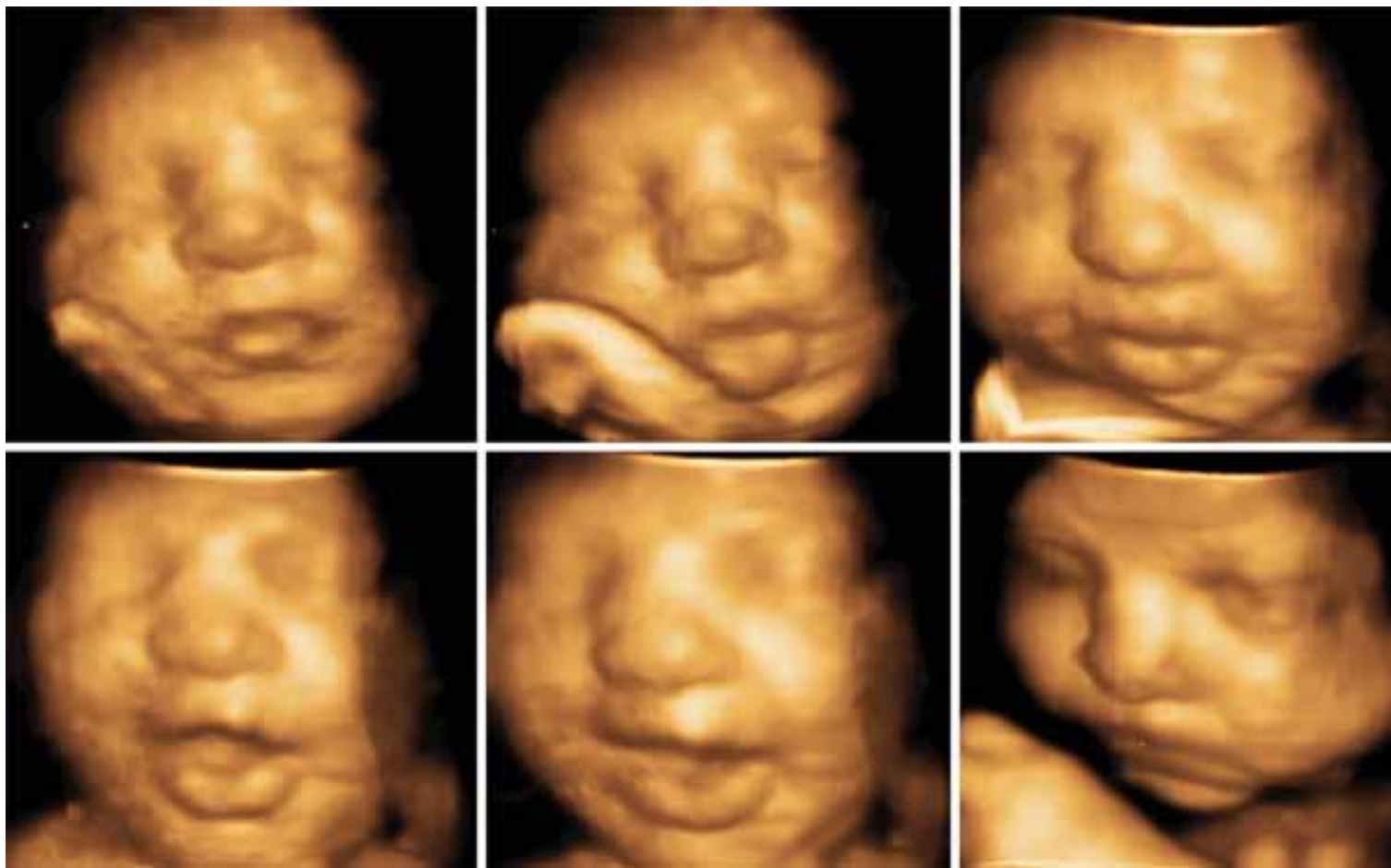

Fig. 9: Tongue expulsion and mouthing
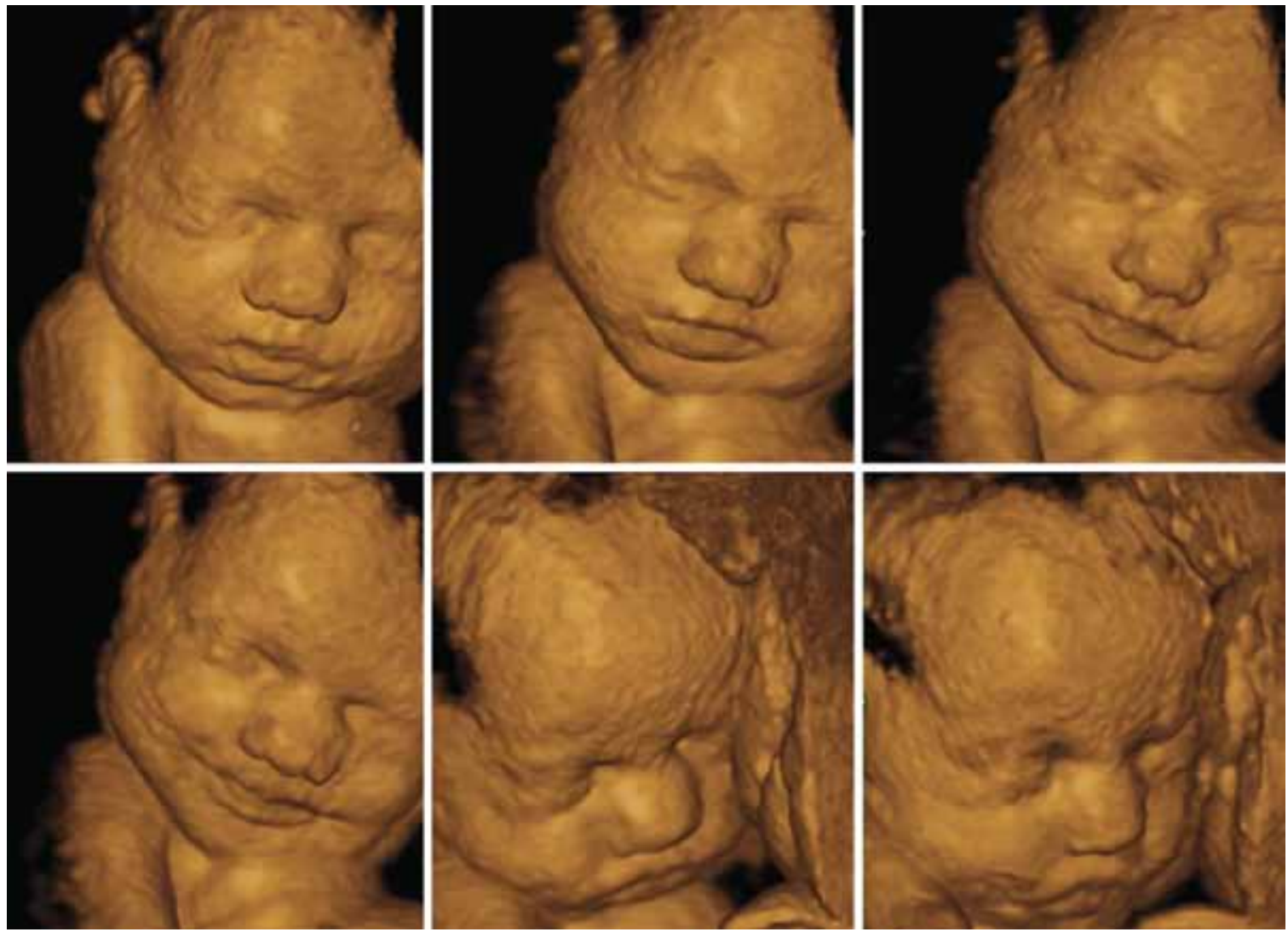

Fig. 10: Smiling

The study demonstrated the potential of KANET to detect and discriminate normal from borderline and abnormal fetal behavior in normal and in high-risk pregnancies. Other neonates are still followed up in this study, in order to reach safe conclusions. ${ }^{105}$
Honemeyer et al studied 100 fetuses, who underwent, between 28 and 38 weeks of gestation, up to 3 times during their pregnancy assessment by KANET. The fetuses were followed-up postnatally, immediately after delivery and again at 12 weeks of life, with systematic 
neurological assessment by the neonatologist. The results from the scoring systems of pre-and postnatal evaluation were compared. Results showed that a normal prenatal KANET score is significantly predictive of normal postnatal neurological assessment of the newborn immediately after delivery and at 12 weeks of life. The authors concluded that that normal antenatal KANET scores is a very good predictor of a normal postnatal neurological outcome. ${ }^{111}$

Lebit et al used part of the KANET to assess fetal movements throughout pregnancy in 144 low-risk pregnancies, between 7 and 38 weeks of gestation, concluding to a specific pattern of fetal behavior for each trimester of pregnancy. ${ }^{93}$ The authors noticed that in the first trimester fetal movements grow rapidly in frequency and complexity, while in the second half of pregnancy the motor behavior significantly increases in frequency and variability. Facial expressions and eye movements also appear in second trimester, with the first eye movements starting at about 18 weeks. In late pregnancy fetal movements show a decline and the periods of rest start to grow. This decrease is rather a consequence of the brain maturation process rather than reduced amount of amniotic fluid. ${ }^{86,92}$ They concluded that dynamic evaluation of fetal behavior reflects directly the processes of maturation and development of the central nervous system and that KANET test has much to offer in the assessment of fetal behavior. ${ }^{93}$

An important study was that by Talic et al which aimed to assess the differences in fetal behavior in both normal fetuses and fetuses with cerebral ventriculomegaly, by using KANET. They studied 240 fetuses between 32 and 36 weeks of gestation, 140 fetuses with venticulomegaly and 100 normal fetuses. Six percent of the fetuses from the low risk-control group had pathological KANET scores, while $34.9 \%$ of the fetuses with ventriculomegaly had pathological KANET. The largest number of abnormal KANET scores was found in 22 fetuses with severe ventriculomegaly, accompanied by other structural abnormalities (Dandy-Walker, Arnold-Chiari, agenesis of the corpus callosum, holoprosencephaly, encephalocele, spina bifida, choroid plexus cyst, osteogenesis imperfect type II, thanatophoric dysplasia type I and Meckel Gruber syndrome). There were no fetuses with abnormal KANET in the group of isolated mild and moderate ventriculomegaly. The authors concluded that prenatal neurological findings of the fetuses by application of KANET test is in concordance with their postnatal outcome and that evaluation of fetal behavior by KANET in fetuses with cerebral ventriculomegaly had the potential to detect fetuses with abnormal behavior, adding a functional dimension of the central nervous system evaluation to the brain morphology. Also, the degree of ventriculomegaly and the presence of coexisting congenital malformations, appeared to be important factors determining the final KANET score. The results of this study were very positive and showed that KANET could provide useful information for the correct assessment and counseling of patients with a common finding, such as ventriculomegaly, the significance of which is not well defined. ${ }^{107}$

More recently, our collaborators from Qatar, AboYaqoub et al studied 40 pregnant women with high risk pregnancies for neurological abnormalities, between 20 and 38 weeks of gestation using KANET scoring system and compared the results with 40 low-risk cases, in order to determine the role of $4 \mathrm{D}$ ultrasound in prenatal assessment of fetal neurobehavior and in the prediction of adverse neurological outcome. The difference in the range of KANET score was significant between the 2 groups and all cases with abnormal KANET proved to be abnormal postnatally, whereas those with normal or borderline KANET scores were neurologically normal at least in the early neonatal period that they were assessed. The parameters that were significantly different between the two groups were: isolated head anteflexion, isolated eye blinking, facial expressions, mouth movements, isolated hand movements hand-to-face movements, finger movements and general movements. For isolated leg movements and cranial sutures, the difference was not significant. ${ }^{104}$

Vladareanu et al applied KANET in 196 singleton pregnancies (61 low risk and 135 high-risk patients) between 24 and 38 weeks of gestation in a period of 3 years. Most fetuses in the study who obtained normal KANET score belonged to the low-risk pregnancies, those who obtained borderline score were fetuses with intrauterine growth restriction (IUGR) and with increased resistance index (RI) of middle cerebral artery (MCA) and most fetuses with abnormal KANET score derived from pregnancies complicated by threatened preterm delivery with PPROM. There was statistical significant difference in fetal movements in the two groups. In normal pregnancies, most fetuses (93.4\%) achieved a normal KANET score compared to $78.5 \%$ of the fetuses from high-risk pregnancies. Borderline and abnormal scores were dominant in high-risk pregnancies. In the highrisk pregnancy group, most abnormal KANET scores were in pregnancies complicated by threatened preterm delivery with PPROM (25\%). Most fetuses with pregnancies complicated by IUGR with MCA RI index changes and with hypertension above 160/100 $\mathrm{mm} \mathrm{Hg}$ achieved borderline score $(50 \%)$. The highest percentage of normal fetal movements was found in pregnancies complicated by $\mathrm{Rh}$ isoimmunization without hydrops fetalis (96\%). The characteristics of reduced speed and amplitude were 
found in the threatened preterm delivery group. There was a reduction of both number and duration of general movements in the IUGR group. The IUGR fetuses moved less and their general movements were poorly organized. Alterations in the quality of fetal movements were accompanied by considerable decrease in the quantity of fetal movements. The authors concluded that KANET can be useful for early diagnosis of neurological disorders that become manifest in perinatal and postnatal period. ${ }^{112}$

Honemeyer et al studied 56 singleton pregnancies (24 low-risk and 32 high-risk cases) between 28 and 38 weeks of gestation and applied serial KANETs on them, performing a total of 117 tests in total. They did not identify any abnormal KANET scores, but two thirds of the borderline scores occurred in the high-risk pregnancies. Because they performed more than one KANET in each pregnancy they introduced the average KANET score, which derived from the scores of each fetus during pregnancy. Only one fetus had a borderline average KANET score, and this fetus who belonged to the highrisk group, was the only one out of 56 pregnancies who had an abnormal early neurological outcome. When the authors compared all the 18 borderline KANET scores with fetal diurnal rhythm based on maternal observation, they noticed that $89 \%$ of the borderline scores of the at-risk group were recorded at times that the mothers characterized them as active periods, compared with $33.3 \%$ in the low-risk pregnancies. The authors concluded that KANET is suggestive of expressing the risk for neurodevelopmental fetal disorders, but the connection of fetal diurnal rhythm and pregnancy risk status should be investigated further. ${ }^{113}$

Kurjak et al studied 869 high and low-risk singleton pregnancies taking under consideration the results of the Doppler studies of umbilical and middle cerebral arteries, and noticed that fetal behavior was significantly different between the normal group and the following subgroups of fetuses: fetal growth restriction (FGR), gestational diabetes mellitus, threatened preterm birth, antepartum hemorrhage, maternal fever, sibling with cerebral palsy, and polyhydramnios. ${ }^{123}$ The authors concluded that their study showed a new clinical application of the KANET test in early identification of fetuses at risk for adverse neurological outcome.

\section{CONCLUSION}

One of the greatest challenges of obstetrical ultrasonography is the better understanding of fetal neurological function. ${ }^{95,114}$ Neurological problems, such as cerebral palsy are poorly understood and often falsely attributed to intrapartum events, while for the majority of cerebral palsy cases it has been proven that the causative pathway starts long before delivery. ${ }^{115-117}$ Several attempts have been made in order to define normal and abnormal fetal neurological function and to develop a method of assessment of the integrity of the fetal nervous system, but still without satisfactory sensitivity. ${ }^{103,116-118}$

Fetal behavioral patterns are directly reflecting developmental and maturational processes of fetal central nervous system. ${ }^{116-118}$ It has been suggested that the assessment of fetal behavior during different periods of gestation may provide valuable information about normal and abnormal brain development, and contribute to the early diagnosis of various structural or functional neurological abnormalities. ${ }^{80}$ The introduction of three and four dimensional ultrasound (3D and 4D) allowed real time assessment of fetal behavior. Details of the fetal face, and especially movements of mouth, eyes (facial expressions) and fingers have been made possible with the introduction of 4D ultrasound. ${ }^{31,119-122}$ KANET is the first method that attempted to use 4D ultrasound in order to assess and combine parameters of fetal behavior and form a scoring system that would assess the fetus in a comprehensive and systematic approach, in the same way that neonatologists perform a neurological assessment in newborns during the first days of their life, in order to determine their neurological status. ${ }^{93}$ KANET appears to be able to identify functional characteristics of the fetus that predict normal and abnormal neurological development and hopefully future results of the prospective multicentric studies that are taking place at the moment in the next few years it will provide more information on fetal neurology. Such information will be of great value in counseling mothers of high-risk pregnancies, like for example in cases with previous child with cerebral palsy and also provide valuable evidence for cases of litigation.

\section{REFERENCES}

1. Salihagic-Kadic A, Kurjak A, Medic M, Andonotopo W, Azumendi G. New data about embryonic and fetal neurodevelopment and behaviour obtained by 3D and 4D sonography. J Perinat Med 2005;33(6):478-490.

2. Pomeroy SL, Voipe JJ. Development of the nervous system. In: Polin RA, Fox, WW, editors. Fetal and neonatal physiology. Philadelphia-London-Toronto-Montreal-Sydney-Tokyo: WB Saunders Company 1992;1491-1509.

3. O'Rahilly R, Muller F. Minireview: Summary of the initial development of the human central nervous system. Teratology 1999;60(1):39-41.

4. Kostovic I, Judas M, Petanjek Z, Simic G. Ontogenesis of goaldirected behavior: anatomo-functional considerations. Int J Psychophysiol 1995;19(2):85-102.

5. Schaher S. Determination and differentiation in the development of the nervous system. In: Kandel ER, Schwartz JH, editors. Principles of Neural Science. 2nd ed. New York: Elsevier Science Publishing 1985:730-732. 
6. Kostovic I. Prenatal development of nucleus basalis complex and related fibre system in man: a histochemical study. Neurosci 1986;17(4):1047-1077.

7. Okado N. Onset of synapse formation in the human spinal cord. J Comp Neurol 1981;201(2):211-219.

8. Kostovic I. Zentralnervensystem. In: Hinrichsen KV, editor. Humanembryologie. Berlin: Springer-Verlag, 1990:381-448.

9. Prechtl FHR. Ultrasound studies of human fetal behaviour. Early Hum Dev 1985;12(2):91-98.

10. lanniruberto A, Tajani E. Ultrasonographic study of fetal movements. Semin Perinatal 1981;5(2):175-181.

11. Goto S, Kato TK. Early movements are useful for estimating the gestational weeks in the first trimester of pregnancy. In: Levski RA, Morley P, editors. Ultrasound ,82. Oxford: Pergamon Press, 1983:577-582.

12. Joseph R. Fetal brain and cognitive development. Dev Rev 2000;20(1):81-98.

13. de Vries JIP, Visser GHA, Prechtl HFR. The emergence of fetal behavior I. Qualitative aspects. Early Hum Dev 1982;7(4):301-322.

14. Kostovic I, Rakic P. Development of prestriate visual projections in the monkey and human fetal cerebrum revealed by transient cholinesterase staining. J Neurosci 1984;4(1):25-42.

15. D'Elia A, Pighetti M, Moccia G, Santangelo N. Spontaneous motor activity in the normal fetus. Early Human Dev 2001;65(2):139-144.

16. Prechtl HFR, Einspieler C. Is neurological assessment of the fetus possible? Eur J Obstet Gynecol Reprod Biol 1997;75(1):81-84.

17. Roodenburg PJ, Wladimiroff JW, van Es A, Prechtl HFR. Classification and quantitative aspects of fetal movements during the second half of pregnancy. Early Hum Dev 1991;25(1):19-35.

18. Prechtl FHR. Qualitative changes of spontaneous movements in fetus and preterm infant are a marker of neurological dysfunction. Early Hum Dev 1990;23(3):151-158.

19. Kurjak A, Azumendi G, Vecek N, Kupesic S, Solak M, Varga D, Chervenak F. Fetal hand movements and facial expression in normal pregnancy studied by four-dimensional sonography. J Perinat Med 2003;31(6):496-508.

20. Andonotopo W, Stanojevic M, Kurjak A, AzumendiG, Carrera JM. Assessment of fetal behavior and general movements by four-dimensional sonography. Ultrasound Rev Obstet Gynecol 2004;4(2):103-114.

21. Kurjak A, Stanojevic M, Azumendi G, Carrera JM. The potential of four-dimensional (4D) ultrasonography in the assessment of fetal awareness. J Perinat Med 2005;33(1):46-53.

22. Kurjak A, Pooh RK, Carrera JM, Merce L, Salihagic-Kadic A, Andonotopo W. Structural and functional early human development assessed by three-dimensional (3D) and four-dimensional (4D) sonography. Fertil Steril 2005;84(5): 1285-1299.

23. Kurjak A, Miskovic B, Andonotopo W, Stanojevic M, Azumendi G, Vrcic H. How useful is 3D and 4D ultrasound in perinatal medicine. J Perinat Med 2007;35(1):10-27.

24. Andonotopo W, Medic M, Salihagic-Kadic A, Milenkovic D, Maiz N, Scazzocchio E. The assessment of embryonic and fetal neurodevelopment in early pregnancy: comparison between 2D and 4D sonographic scanning. J Perinat Med 2005;33(5):406-414.

25. Kurjak A, Stanojevic M, Andonotopo W, Scazzocchio-Duenas E, Azumendi G, Carrera JM. Fetal behavior assessed in all three trimesters of normal pregnancy by four-dimensional ultrasonography. Croat Med J 2005;46(5):772-780.
26. Pooh RK, Ogura T. Normal and abnormal fetal hand positioning and movement in early pregnancy detected by threeand four-dimensional ultrasound. Ultrasound Rev Obstet Gynecol 2004;4(2):46-51.

27. Kurjak A, Stanojevic M, Andonotopo W, Salihagic-Kadic A, Azumendi G, Carrera JM. Behavioral pattern continuity from prenatal to postnatal life — a study by four-dimensional (4D) ultrasonography. J Perinat Med 2004;32(4):346-353.

28. Andonotopo W, Kurjak A, Kosuta MI. Behavior of anencephalic fetus studied by $4 \mathrm{D}$ sonography. J Matern Fetal Neonatal Med 2005;17(2):165-168.

29. Andonopo W, Kurjak A. The assessment of fetal behavior of growth restricted fetuses by $4 \mathrm{D}$ sonography. J Perinat Med 2006;34(6):471-478.

30. Kurjak A, Andonotopo W, Hafner T, Salihagic-Kadic A, Stanojevic M, Azumendi G, Ahmed B, Carrera JM, Troyano JM. Normal standards for fetal neurobehavioural developments -longitudinal quantification by four-dimensional sonography. J Perinat Med 2006;34(1):56-65.

31. Kurjak A, Azumendi G, Andonotopo W, Salihagic Kadic A. Three- and four-dimensional ultrasonography for the structural and functional evaluation of the fetal face. Am J Obstet Gynecol 2007;196(1):16-28.

32. Walusinski O, Kurjak A, Andonotopo W, Azumendi G. Fetal yawning assessed by 3D and 4D sonography. Ultrasound Rev Obstet Gynecol 2005;5(3):210-217.

33. Rosenbaum P, Paneth N, Leviton A, Goldstein M, Bax M, Damiano D, Dan B, Jacobsson B. A report: the definition and classification of cerebral palsy April 2006. Dev Med Child Neurol 2007;109 (suppl.):8-14.

34. Palmer FB. Strategies for the early diagnosis of cerebral palsy. J Pediatr 2004;145:S8-S11.

35. Walstab JE, Bell RJ, Reddihough DS, Brennecke SP, Bessell CK, Beischer NA. Factors identified during the neonatal period associated with risk of cerebral palsy. Australian and New Zeland J Obstet Gynecol 2004;44(4):342-346.

36. Nelson KB, Ellenberg JH. Neonatal signs as predictors of cerebral palsy. Pediatrics 1979;64(2):225-232.

37. Amiel Tison C, Gosselin J, Kurjak A. Neurosonography in the second half of fetal life: a neonatologist point of view. J Perinat Med 2006;34(6):437-446.

38. Gosselin J, Gahagan S, Amiel-Tison C. The Amiel-Tison neurological assessment at term: conceptual and methodological continuity in the course of follow-up. Ment Retard Dev Disabil Res Rev 2005;11(1):34-51.

39. Amiel-Tison C. Update of the Amiel-Tison Neurological assessment for the term neonate or at 40 weeks corrected age. Pediatr Neurol 2002;27(3):196-212.

40. Volpe JJ. Neurological examination: Normal and abnormal features. In Neurology of the newborn. 4th ed. Philadelphia: WB Saunders, 2001:127.

41. Einspieler C, Prechtl HFR, Bos AF, Ferrari F, Cioni G. Prechtl's method on the qualitative assessment of general movements in preterm, term and young infants. Mac Keith Press, Cambridge, 2004.

42. Hadders-Algra M. General movements: a window for early identification of children at high risk for developmental disorders. J Pediatr 2004;145(Suppl 2):S12-S18.

43. Hadders-Algra M, Klip-Van den Niewcendijk WJ, Martijn A, van Eyken L. Assessment of general movements: towards a 
better understanding of a sensitive method to evaluate brain function in young infants. Dev Med Child Neurol 1997;39(2): 89-99.

44. Bekedam DJ, Visser GHA, de Vries JJ, Prechtl HFR. Motor behaviour in the growth retarded fetus. Early Human Dev 1985;12(2):155-165.

45. Cioni G, Prechtl HF. Preterm and early post term motor behaviour in low-risk premature infants. Early Hum Dev 1990;23(3):159-191.

46. Seme-Ciglenečki P. Predictive value of assessment of general movements for neurological development of high-risk preterm infants: comparative study. Croat Med J 2003;44(6):721-727.

47. Cioni G, Prechtl HFR, Ferrari F, Paolicelli PB, Einspieler C, Roversi MF. Which better predicts later outcome in full term infants: quality of general movements or neurological examination? Early Hum Dev 1997;50(1):71-85.

48. Einspieler C, Prechtl HF, Ferrari F, Cioni G, Bos AF. The qualitative assessment of general movements in preterm, term and young infants review of the methodology. Early Hum Dev 1997;50(1):47-60.

49. Ferrari F, Cioni G, Einspieler C, Roversi MF, Bos AF, Paolicelli PB, Ranzi A, Prechtl HF. Cramped synchronized general movements in preterm infants as an early marker for cerebral palsy. Arch Pediatr Adolesc Med 2002;156(5):460-467.

50. Prechtl HFR. State of the art of a new functional assessment of the young nervous system. An early predictor of cerebral palsy. Early Hum Dev 1997;50(1):1-11.

51. Kurjak A, Jackson D, editors. An atlas of three- and fourdimensional sonography in obstetrics and gynecology. Taylor and Francis Group: London, 2004.

52. Sarnat HB. Anatomic and physiologic correlates of neurologic development in prematurity. In: Sarnat HB, editor. Topics in neonatal neurology. New York: Grune and Stratton, 1984:1-24.

53. Sarnat HB. Functions of the corticospinal and corticobulbar tracts in the human newborns. Can J Neurol Sci 1989;16(2):157-160.

54. Amiel-Tison C. Clinical assessment of the infant nervous system. In: Levente MI, Chervenak FA, Whittle M, editors. Fetal and Neonatal Neurology and Neurosurgery. 3rd ed. Churchill Livingstone: London, 2001:99-120.

55. Salisbury AL, Duncan Fallone M, Lester B. Neurobehavioral assessment from fetus to Infant: the NICU network neurobehavioral scale and the fetal neurobehavioral coding system. Ment Retard Dev Disabil Res Rev 2005;11(1):14-20.

56. de Vries JIP, Visser GHA, Prechtl HFR. Fetal motility in the first half of pregnancy. In: Prechtl HFR, editor. Continuity of neural functions from prenatal to postnatal life. Clin Dev Med 94 Oxford, Blackwell, 1984:46-63.

57. Kostović I, Seress L, Mrzljak L, Judaš M. Early onset of synapse formation in the human hippocampus: a correlation with Nissl-Golgi architectonics in 15- and 16.5-week-old fetuses. Neurosc 1989;30(1):105-116.

58. Mutch L, Alberman E, Hagberg B, Kodama K, Perat MV. Cerebral palsy epidemiology: where are we now and where are we going? Dev Med Child Neurol 1992;34(6):547-551.

59. Bax M, Goldstein M, Rosenbaum P, Leviton A, Paneth N, Dan B, Jacobsson B, Damiano D, Executive Committee for the definition of cerebral palsy. Proposed definition and classification of cerebral palsy. Dev Med Child Neurol 2005;47(8):571-576.

60. Sankar C, Mundkur N. Cerebral palsy-definition, classification, etiology and early diagnosis. Ind J Pediatr 2005;72(10):865-868.
61. Shapiro BK. Cerebral palsy: a reconceptualization of the spectrum. J Pediatr 2004;145 (Suppl 2):S3-7.

62. Amiel-Tison C, Gosselin J, Infante-Rivard C. Head growth and cranial assessment at neurological examination in infancy. Dev Med Child Neurol 2002;44(9):643-648.

63. Pooh RK, Pooh K, Nakagawa Y, Nishida S, Ohno Y. Clinical application of three-dimensional ultrasound in fetal brain assessment. Croat Med J 2000;41(3):245-251.

64. Campbell S, Lees C, Moscoso G, Hall P. Ultrasound antenatal diagnosis of cleft palate by a new technique: the 3D 'reverse face' view. Ultrasound Obstet Gynecol 2005;25(1):12-18.

65. DiPietro JA. Neurobehavioral assessment before birth. Ment Retard Dev Disabil Res Rev 2002;11(1):4-13.

66. Yigiter AB, Kavak ZN. Normal standards of fetal behavior assessed by four-dimensional sonography. J Matern Fetal Neonatal Med 2006 Nov;19(11):707-721.

67. Rees S, Harding R. Brain development during fetal life: influences of the intrauterine environment. Neurosci Lett 2004 May 6;361(1-3):111-114.

68. Kurjak A, Carrera JM, Stanojevic M, Andonotopo W, Azumendi G, Scazzocchio E, Medic E, Salihagic-Kadic A. The role of 4D sonography in the neurological assessment of early human development. Ultrasound Rev Obstet Gynecol September 2004;4(3):148-159.

69. Eidelman AI. The living fetus e dilemmas in treatment at the edge of viability. In: Blazer S, Zimmer EZ, editors. The embryo: scientific discovery and medical ethics. Basel: Karger; 2005. p. $351 \mathrm{e} 70$.

70. Stanojevic M, Zaputovic S, Bosnjak AP. Continuity between fetal and neonatal neurobehavior. Semin Fetal Neonatal Med 2012 Jul 16.

71. Haak P, Lenski M, Hidecker MJ, Li M, Paneth N. Cerebral palsy and aging. Dev Med Child Neurol 2009 Oct;51 Suppl 4:16-23.

72. Einspieler C, Prechtl HF. Prechtl's assessment of general movements: a diagnostic tool for the functional assessment of the young nervous system. Ment Retard Dev Disabil Res Rev 2005;11(1):61-67.

73. Moster D, Wilcox AJ, Vollset SE, Markestad T, Lie RT. Cerebral palsy among term and post-term births. JAMA 2010 Sep 1;304(9):976-982.

74. Almli CR, Ball RH, Wheeler ME. Human fetal and neonatal movement patterns: gender difference and fetal-to-neonatal continuity. Dev Psychobiol 2001;38:252-273.

75. DiPietro JA, Bronstein MH, Costigan KA, Pressmen EK, Hahn CS, Painter K, Smith BA, Yi LJ. What does fetal movement predict about behaviorduring the first 2 years of life? Dev Phych 2002;40:358-371.

76. DiPetro JA, Hodson DM, Costigan KA, Johnson TR. Fetal antecedents of infant temperament. Child Dev 1996;67: 2568-2583.

77. DiPietro JA, Costigan KA, Pressman EK. Fetal state concordance predicts infant state regulation. Early Hum Dev 2002; 68:1-13.

78. Thoman EB, Denenberg VH, Sievel J, Zeidner LP, Becker P. State organization in neonate: developmental inconsistency indicates risk for developmental dysfunction. Neuropediatrics 1981;12:45-54.

79. St James-Roberts I, Menon-Johansson P. Predicting infant crying from fetal movement data: an exploratory study. Early Hum Dev 1999;54:55-62. 
80. de Vries JI, Visser GH, Prechtl HF. The emergence of fetal behaviour. II. Quantitative aspects. Early Hum Dev 1985 Nov;12(2):99-120.

81. de Vries JI, Visser GH, Prechtl HF. The emergence of fetal behaviour. III. Individual differences and consistencies. Early Hum Dev 1988 Jan;16(1):85-103.

82. de Vries JI, Visser GH, Prechtl HF. The emergence of fetal behaviour. I. Qualitative aspects. Early Hum Dev 1982 Dec;7(4):301-322.

83. Nijhuis JG, editor. Fetal behaviour: developmental and perinatal aspects. Oxford, Oxford University Press: 1992.

84. Kurjak A, Luetic AT. Fetal neurobehavior assessed by threedimensional/four dimentional sonography. Zdrav Vestn 2010;79:790-799.

85. Salihagic-Kadic A, Medic M, Kurjak, et al. 4D sonography in the assessment of fetal functional neurodevelopment and behavioural patterns. Ultrasound Rev Obstet Gynecol 2005;5(1):1-15.

86. Kurjak A, Pooh R, Tikvica A, et al. Assessment of fetal neurobehavior by 3D/4D ultasound. Fetal Neurol 2009: 222-250.

87. Lebit DF, Vladareanu PD. The Role of $4 \mathrm{D}$ ultrasound in the assessment of fetal behaviour. Maedica (Buchar) 2011 Apr;6(2):120-127.

88. Merz E, Abramowicz JS. 3D/4D Ultrasound in prenatal diagnosis: Is it time for routine use? Clin Obstet Gynecol 2012 Mar;55(1):336-351.

89. Kurjak A, Vecek N, Hafner T, Bozek T, Funduk-Kurjak B, Ujevic B. Prenatal diagnosis: what does four-dimensional ultrasound add? J Perinat Med 2002;30(1):57-62.

90. Kurjak A, Vecek N, Kupesic S, Azumendi G, Solak M. Four dimensional ultrasound: how much does it improve perinatal practice? In: Carrera JM, Chervenak FA, Kurjak A, editors. Controversies in perinatal medicine, studies on the fetus as a patient. A CRC press company Parthenon Publishing New York 2003. p. 222.

91. Kurjak A, Carrera J, Medic M, Azumendi G, Andonotopo W, Stanojevic M. The antenatal development of fetal behavioral patterns assessed by four-dimensional sonography. J Matern Fetal Neonatal Med 2005 Jun;17(6):401-416.

92. Kurjak A, Pooh R, Tikvica A, et al. Assessment of fetal neurobehaviour by 3D/4D ultrasound. Fetal Neurol 2009. p. 222-250.

93. Kurjak A, Tikvica A, Stanojevic M, Miskovic B, Ahmed B, Azumendi G, Di Renzo GC. The assessment of fetal neurobehavior by three-dimensional and four-dimensional ultrasound. J Matern Fetal Neonatal Med 2008 Oct;21(10):675-684.

94. Kurjak A, Miskovic B, Stanojevic M, Amiel-Tison C, Ahmed B, Azumendi G, Vasilj O, Andonotopo W, Turudic T, SalihagicKadic A. New scoring system for fetal neurobehavior assessed by three- and four-dimensional sonography. J Perinat Med 2008;36(1):73-81.

95. Tomasovic S, Predojevic M. 4D Ultrasound - Medical devices for recent advances on the etiology of cerebral palsy. Acta Inform Med 2011;19(4):228-234.

96. Stanojevic M, Kurjak A, Salihagic-Kadic A, et al. Neurobehavioral continuity from fetus to neonate. J Perinat Med 2011;39(2):171-177.

97. Stanojevic M, Talic A, Miskovic B, Vasilj O, Naim Shaddad A, Ahmed B, Salihagic Kadic A, Predojevic M,
Vladareanu R, Lebit D, et al. An attempt to standardize Kurjak's antenatal neurodevelopmental test: osaka consensus statement. DSJUOG 2011 Oct-Dec;5(4):p 317-329.

98. Pooh RK, Pooh K. Fetal ventriculomegaly. Donald School J Ultrasound Obstet Gynecol 2007;1(4):40-46.

99. Kurjak A, Ahmed B, Abo-Yaquab S, Younis M, Saleh H, Naim Shaddad A, Vasilj O, Al Bahar AJ, Miskovic B, Khenyab N. An attempt to introduce neurological test for fetus based on 3D and 4D sonography. Donald School J Ultrasound Obstet Gynecol 2008;1(4):40-46.

100. Kuno A, Akiyama M, Yamashiro C, Tanaka H, Yanagihara $\mathrm{T}$, Hata T. Three-dimensional sonographic assessment of fetal behavior in the early second trimester of pregnancy. J Ultrasound Med 2001 Dec;20(12):1271-1275.

101. Koyanagi T, Horimoto N, Maeda H, Kukita J, Minami T, Ueda K, Nakano H. Abnormal behavioral patterns in the human fetus at term: correlation with lesion sites in the central nervous system after birth. J Child Neurol 1993 Jan;8(1):19-26.

102. Stanojevic M, Kurjak A. Continuity between Fetal and Neonatal Neurobehavior. Donald School J Ultrasound Obstet Gynecol 2008;2(3):64-75.

103. Kurjak A, Abo-Yaqoub S, Stanojevic M, Yigiter AB, Vasilj O, Lebit D, Shaddad AN, Ahmed B, Kavak ZN, Miskovic B. The potential of $4 \mathrm{D}$ sonography in the assessment of fetal neurobehavior multicentric study in high-risk pregnancies. J Perinat Med 2010;38(1):77-82.

104. Abo-Yaqoub S, Kurjak A, Mohammed AB, Shadad A, AbdelMaaboud $\mathrm{M}$. The role of 4-D ultrasonography in prenatal assessment of fetal neurobehaviour and prediction of neurological outcome. J Matern Fetal Neonatal Med 2012 Mar;25(3):231-236.

105. Talic A, Kurjak A, Ahmed B, Stanojevic M, Predojevic M, Kadic AS, Di Renzo GC. The potential of 4D sonography in the assessment of fetal behavior in high-risk pregnancies. J Matern Fetal Neonatal Med 2011 Jul;24(7):948-954.

106. Miskovic B, Vasilj O, Stanojevic M, Ivanković D, Kerner M, Tikvica A. The comparison of fetal behavior in high-risk and normal pregnancies assessed by four dimensional ultrasound. J Matern Fetal Neonatal Med 2010 Dec;23(12): 1461-1467.

107. Talic A, Kurjak A, Stanojevic M, Honemeyer U, Badreldeen A, Direnzo GC. The assessment of fetal brain function in fetuses with ventrikulomegaly: the role of the KANET test. J Matern Fetal Neonatal Med 2012;25(8):1267-1272.

108. Horimoto N, Koyanagi T, Maeda H, Satoh S, Takashima T, Minami T, Nakano H. Can brain impairment be detected by in utero behavioural patterns? Arch Dis Child 1993 Jul;69(1 Spec No):3-8.

109. Morokuma S, Fukushima K, Yumoto $Y$, Uchimura M, Fujiwara A, Matsumoto M, Satoh S, Nakano H. Simplified ultrasound screening for fetal brain function based on behavioral pattern. Early Hum Dev 1982;6(2):177-195.

110. Nijhuis JG, Prechtl HF, Martin CB, Bots RS. Are there behavioral states in the human fetus? Early Hum Dev 1982;6(2): 177-195.

111. Honemeyer U, Kurjak A. The use of KANET test to assess fetal CNS function. First 100 cases. 10th World Congress of Perinatal Med 2011 Nov;8-11. 
112. Vladareanu R, Lebit D, Constantinescu S. Ultrasound assessment of fetal neurobehaviour in high-risk pregnancies. DSJUOG 2012 Apr-Jun;6(2):132-147.

113. Honemeyer U, Talic A, Therwat A,Paulose L, Patidar R. The clinical value of KANET in studying fetal neurobehavior in normal and at-risk pregnancies. J Perinat Med 2013;41(2):187-197.

114. Hepper PG. Fetal behavior: why so skeptical? Ultrasound Obstet Gynecol 1996;8(3):145-148.

115. Greenwood C, Newman S, Impey L, Johnson A. Cerebral palsy and clinical negligence litigation: a cohort study. BJOG 2003 Jan;110(1):6-11.

116. Strijbis EM, Oudman I, van Essen P, MacLennan AH. Cerebral palsy and the application of the international criteria for acute intrapartum hypoxia. Obstet Gynecol 2006 Jun;107(6):1357-1365.

117. de Vries JI, Fong BF. Changes in fetal motility as a result of congenital disorders: an overview. Ultrasound Obstet Gynecol 2007 May;29(5):590-599.

118. de Vries JI, Fong BF. Normal fetal motility: an overview. Ultrasound Obstet Gynecol 2006 Jun;27(6):701-711.

119. Rosier-van Dunné FM, van Wezel-Meijler G, Bakker MP, de Groot L, Odendaal HJ, de Vries JI. General movements in the perinatal period and its relation to echogenicity changes in the brain. Early Hum Dev 2010 Feb;86(2):83-86.
120. Hata T, Kanenishi K, Akiyama M, Tanaka H, Kimura K. Realtime 3-D sonographic observation of fetal facial expression. J Obstet Gynaecol Res 2005 Aug;31(4):337-340.

121. Kozuma S, Baba K, Okai T, Taketani Y. Dynamic observation of the fetal face by three-dimensional ultrasound. Ultrasound Obstet Gynecol 1999 Apr;13(4):283-284.

122. Kurjak A, Predojevic M, Salihagic-Kadic A. Fetal brain function: lessons learned and future challenges of $4 \mathrm{D}$ sonography. Donald School J Ultrasound Obstet Gynecol 2010 Apr-Jun;2(5):85-92.

123. Kurjak A, Talic A, Honemeyer U, Stanojevic M, Zalud I. Comparison between antenatal neurodevelopmental test and fetal Doppler in the assessment of fetal well being. J Perinat Med 2013 Jan;41(1):107-114.

124. Athanasiadis AP, Mikos T, Tambakoudis GP, Theodoridis TD, Papastergiou M, Assimakopoulos E, Tarlatzis BC. Neurodevelopmental fetal assessment using KANET scoring system in low and high risk pregnancies. J Matern Fetal Neonatal Med 2013 Mar;26(4):363-368.

125. Predojević M, Talić A, Stanojević M, Kurjak A, Salihagić Kadić A. Assessment of motoric and hemodynamic parameters in growth restricted fetuses-case study. J Matern Fetal Neonatal Med 2014;27(3):247-251. 